\title{
The Sellaphora pupula species complex (Bacillariophyceae): morphometric analysis, ultrastructure and mating data provide evidence for five new species
}

\author{
David G. Mann ${ }^{1 *}$, Sarah M. McDonald ${ }^{1}$, Micha M. Bayer ${ }^{1}$, Stephen J.M. Droop', Victor A. Chepurnovi,2, \\ Robert E. LOKE ${ }^{3}$, Adrian Ciobanu ${ }^{4}$ And J.M. Hans du BuF ${ }^{3}$ \\ ${ }^{1}$ Royal Botanic Garden Edinburgh, 20 A Inverleith Row, Edinburgh EH3 5LR, UK \\ ${ }^{2}$ Laboratory of Protistology and Aquatic Ecology, Department of Biology, Ghent University, Krijgslaan 281 S8, \\ 9000 Gent, Belgium \\ ${ }^{3}$ Vision Laboratory, Faculty of Sciences and Technology, University of Algarve, 8000-810 Faro, Portugal \\ ${ }^{4}$ Institutul de Informatica Teoretica Iasi, B-dul Carol I nr. 8, 6600 Iasi, Romania
}

\begin{abstract}
D.G. Mann, S.M. McDonald, M.M. Bayer, S.J.M. Droop, V.A. Chepurnov, R.E. Loke, A. Ciobanu and J.M.H. Du Buf. 2004. The Sellaphora pupula species complex (Bacillariophyceae): morphometric analysis, ultrastructure and mating data provide evidence for five new species. Phycologia 43: 459-482.

Morphometric shape analysis and ultrastructural data are provided for six genodemes of the Sellaphora pupula species complex that have been studied during the last 20 years from Blackford Pond, Edinburgh, UK. The demes have previously been shown to be separated by prezygotic reproductive barriers: cells of different demes do not pair, though they may show residual interactions when sexualized. A new morphometric method, contour segment analysis, which was recently developed for diatoms in relation to automated identification, gives a clear separation of all six genodemes and indicates no heterogeneity within each. Legendre shape analysis gives less separation in this instance. All other available data, including molecular sequence data, also support separation of the six demes at species level. Five new species are therefore described: $S$. auldreekie, S. blackfordensis, S. capitata, S. lanceolata and S. obesa. The identity of S. pupula sensu stricto is clarified through designation of epitypes.
\end{abstract}

\section{INTRODUCTION}

Sellaphora pupula (Kützing) Mereschkowsky has become a model system for studying the species concept in diatoms, following the demonstration of reproductive incompatibility between sympatric genodemes (genetically distinct populations: Gilmour \& Heslop-Harrison 1954) in the early 1980s (Mann 1984, 1988a, 1989a, b, 1999, 2001; Mann \& Droop 1996; Mann et al. 1999). Sellaphora pupula has long been known to be morphologically variable (e.g. Hustedt 19271966) and the species complex as a whole is cosmopolitan, occurring in meso- to eutrophic lakes and rivers, generally in the epipelon. In several lakes, but particularly in Blackford Pond, Edinburgh, UK, it has been shown that slight differences in valve shape and size, striation pattern and stria density are markers for populations (demes) that cannot interbreed. Demes can also differ in reproductive biology and susceptibility to chytrid and oomycete parasites (Mann 1989a, 1999). The stability of morphological and other differences has been demonstrated in culture (e.g. Mann et al. 1999) and molecular sequence analysis demonstrates that rapidly evolving parts of the genome, e.g. internal transcribed spacers (ITS), can show extensive divergence - to the extent that sequences can be difficult or impossible to align reliably between some demes (Mann 1999; Behnke et al. 2004). Here, we present morphometric and scanning electron microscope (SEM) evidence relating to the six subtly different demes de-

* Corresponding author (d.mann@ @bge.org.uk). scribed in earlier studies from Blackford Pond (Mann 1989a, 1999; Mann \& Droop 1996), and propose five new species based on these demes.

A number of previous studies of diatoms have involved morphometric analysis of the valve outline. Some of them have involved simple shape measures such as rectangularity, which, although they are nonreciprocal (in the sense that the shape cannot be recovered from the shape descriptor: different shapes can have the same rectangularity), can nevertheless be highly effective in separating semicryptic demes (putative biological species), e.g. of Diploneis Ehrenberg ex Cleve (Droop 1994; Droop et al. 2000). In addition, however, more powerful morphometric methods have been used, involving quantitative shape descriptors such as Legendre polynomials (Stoermer \& Ladewski 1982; Stoermer et al. 1986; Theriot \& Ladewski 1986; Steinman \& Ladewski 1987; Goldman et al. 1990; Rhode et al. 2001; Pappas \& Stoermer 2003) or Fourier coefficients (Mou \& Stoermer 1992; Pappas et al. 2001). These studies all show that extraction of outline shape features, combined with multivariate analysis methods such as principal components analysis (PCA), is an immensely useful tool for detecting and quantifying subtle morphological variation in diatoms, thus providing data to help resolve taxonomic issues at the species level and beyond.

In the present study, we use a method for the quantification of shape that was developed recently as part of the Automatic Diatom Identification and Classification (ADIAC) project (du Buf et al. 1999; du Buf \& Bayer 2002; http://rbg-web2.rbge. org.uk/ADIAC/), based on the subdivision of a diatom's out- 
Table 1. Slide preparations used for image capture, all held at E. The morphometric data for all specimens examined are given in a table available at http://rbg-web2.rbge.org.uk/algae/research/research.htm. England finder and stage coordinate references are valid for the orientation specified.

\begin{tabular}{ll}
\hline \multicolumn{1}{c}{ Slide } & \multicolumn{1}{c}{ Orientation } \\
\hline Blackford Pond 18.12.85 A, thin $11.09 .84 \mathrm{~A}$ & label on right; read from the left \\
Blackford Pond tissue + sediment 1 label on right; read from the right \\
Blackford Pond Dec. 83 Al & label on right; read from the right \\
Blackford Pond 18.12.86, thin 1 & label on right; read from the right \\
Blackford Pond 18.12.86, thin 2 & label on right; read from the right \\
Blackford Pond 9/20.11.87, thin 1 & label on right; read from the right \\
Blackford Pond 31.08.87, thin 1 & label on right; read from the right \\
Blackford Pond Dec. 83, thin 1 & label on right; read from the right \\
Blackford Pond E2612/1 14.1.96 label on right; read from the right \\
Blackford Pond Dec. 83 Mud (tissue) E16/4 & label on left; read from the right \\
\hline
\end{tabular}

line into convex and concave segments. This morphometric method is supplemented and compared with Legendre analysis, as used in previous studies of diatom shape (see above). The resulting data [none of which duplicate the Sellaphora Mereschkowsky data-set used in the ADIAC project by Loke $\&$ du Buf (2002) or Ciobanu \& du Buf (2002)] serve both to help justify the taxonomic separation made here between the six species of the $S$. pupula complex growing sympatrically in Blackford Pond, and to create a well-documented, quantitative basis for future comparisons within the $S$. pupula complex. The results also inform diatomists about the likely value of different shape measures for exploring the variation pattern in Sellaphora and similar diatoms. Valve ultrastructure varies only a little among the six demes studied, in contrast to the diversity within our other model species complex, D. smithii (Brébisson) Cleve-D. fusca (Gregory) Cleve (Droop 1994; Droop et al. 2000), and the demes are less easily separable on this basis than through use of shape and stria pattern. However, there are a few significant differences in ultrastructure and we document these by SEM, again to facilitate future work in the $S$. pupula complex, which probably contains many tens or possibly hundreds of species (Mann \& Droop 1996; Taylor 1996).

\section{MATERIAL AND METHODS}

\section{Sample collection and slide preparation}

Ten slide preparations were used to capture images for the morphometric analysis (Table 1); five slides were already held within the Edinburgh herbarium (E) and five slides were prepared using previously cleaned samples stored in $c$. $90 \%$ ethanol. The slides were all derived from 1 litre samples of mud slurry collected from Blackford Pond, Edinburgh, UK (UK National Grid Reference NT 253709, 70 m altitude), under 0.5-1 m water on various dates between December 1983 and November 1987. Blackford Pond has not been characterized limnologically in any detail. It is a small, approximately oblong $(200 \times 50 \mathrm{~m})$ artificial lake fed by groundwater seepage and underwater springs, lying in parkland in suburban Edinburgh. The lake is home to large populations of waterfowl and it is highly eutrophic. The sediments can become anoxic (e.g. when the lake is ice-covered in winter), although this was less frequent during the 1980s, when our studies began, than it is today.
Living diatoms were separated from the mud using lens tissue, which was removed from the mud surface after 2 days and then destroyed by oxidation with concentrated nitric and sulphuric acids, leaving clean diatom valves and frustules that could be washed and mounted in Naphrax.

\section{Identification and naming of demes}

In the first section of this paper, ' $S$. pupula' is used in the same sense in which it was applied (as Navicula pupula Kützing) in major floras, such as Hustedt (1927-1966), Patrick \& Reimer (1966) and Krammer \& Lange-Bertalot (1986). We regard some recent splits, such as those of Lange-Bertalot \& Metzeltin (1996) as nonproven, because they are based neither on detailed morphometric analyses of the kind we report here, nor on studies of reproductive isolation or genetic separation (cf. Mann 1984, 1989a, 1999; Mann et al. 1999): variation in the $S$. pupula complex is subtle and simple visual comparison is rarely sufficient as a basis for taxon separation, as has been shown in recent molecular genetic studies by Behnke et al. (2004). Specimens examined in the present study were identified to deme by reference to Mann (1984, 1989a, 1999), Mann \& Droop (1996) and Mann et al. (1999), who distinguished six demes in Blackford Pond, called 'capitate', 'rectangular', 'obese', 'lanceolate', 'small' and 'neat'.

\section{Specimen selection for morphometric analysis}

Initially, 250 valves were sampled from seven slides for morphometric analysis. The data set was inspected and the specimens were assigned to demes visually, which revealed that three demes were severely underrepresented, these being 'small' (two valves only), 'neat' (two valves) and 'lanceolate' (three valves). Sampling from three further slides was stratified to collect at least 40 valves of each of the underrepresented demes, giving a final data set of 383 valves. Candidate specimens were only used for image capture if the valve was oriented with the valve face uppermost, level (i.e. with both sides of the valve margin in the same focal plane) and intact, with little or no debris touching the sides of the valve. Slides were scanned systematically using straight transects one field of view wide and all specimens of $S$. pupula encountered were used if they fulfilled the valve quality criteria.

\section{Microscopy, image capture and processing}

For conventional light microscopy (LM), valves were examined using a Reichert Polyvar photomicroscope equipped with 


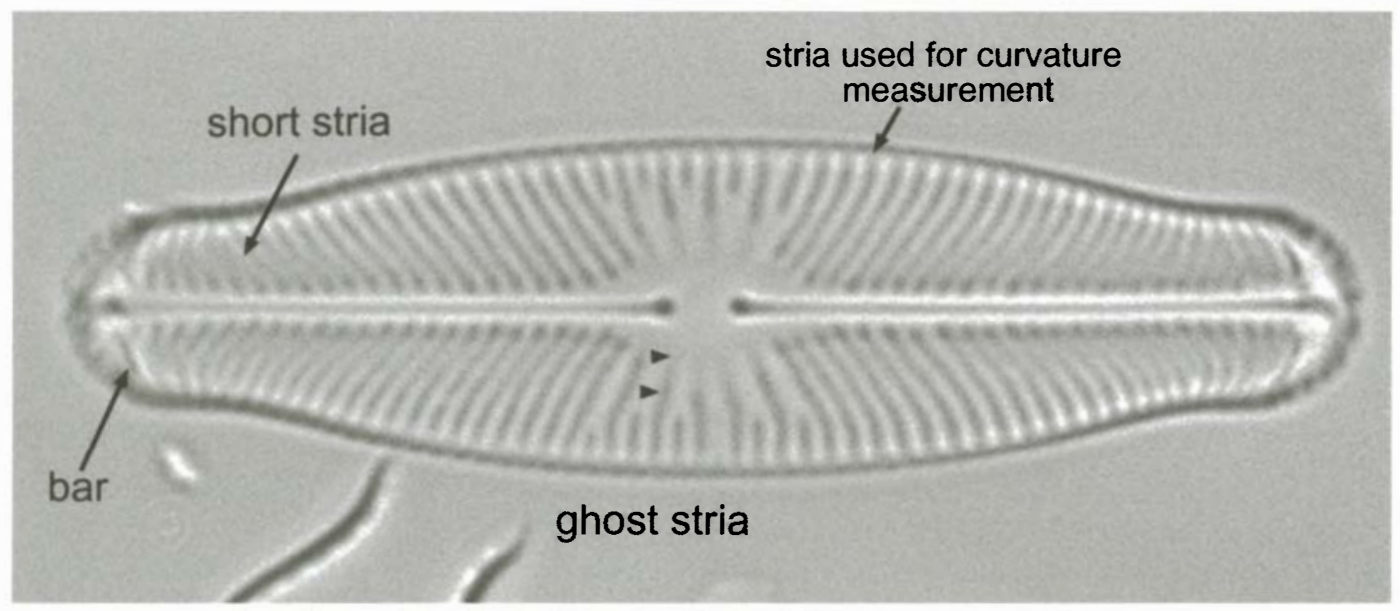

Fig. 1. Sellaphora pupula complex: valve, showing the principal morphological features. The valve is symmetrical, with striae that are radial at the centre and either radial, parallel, or convergent (as here) at the poles. Most striae run from raphe-sternum to margin without interruption, but short striae are often intercalated at the centre or near the poles. At each pole there are thickened bars of silica, which extend across the valve from the helictoglossa, of ten to the valve margins (e.g. Figs 32, 47). There is a hyaline central area, which is sometimes invaded by faint 'ghost' striae, which are extensions of the striae without pores.

bright field (BF) and differential interference contrast (DIC) optics (Leitz, Wetzlar, Germany). Silver halide images (Figs 17-22) were captured using Kodak Technical Pan film (www.kodak.com).

For morphometrics (and the images in Figs 1, 4), images were captured using a digital camera (Kodak MegaPlus ES 1.0, resolution $1008 \times 1018$ pixels) attached to an Axiophot photomicroscope (www.zeiss.com), with a $\times 100$ apochromatic oil immersion lens (NA 1.4) and a $\times 1.6$ Optivar magnification changer. BF optics were used throughout. The acquired image was read into Optimas image analysis software version 6.2 (MediaCybernetics, Silver Spring, MD, USA) and saved as an 8-bit greyscale TIFF file with the background standardized to a greyscale value of $185 \pm 5$. For each specimen, three images representing different focal planes were acquired; these were focused on the valve outline, the striae, and the silica bars at the valve poles, respectively. Care was taken to focus on the valve edge for the outline focus rather than on the mantle, to avoid introducing extra shape and size variation as a result of

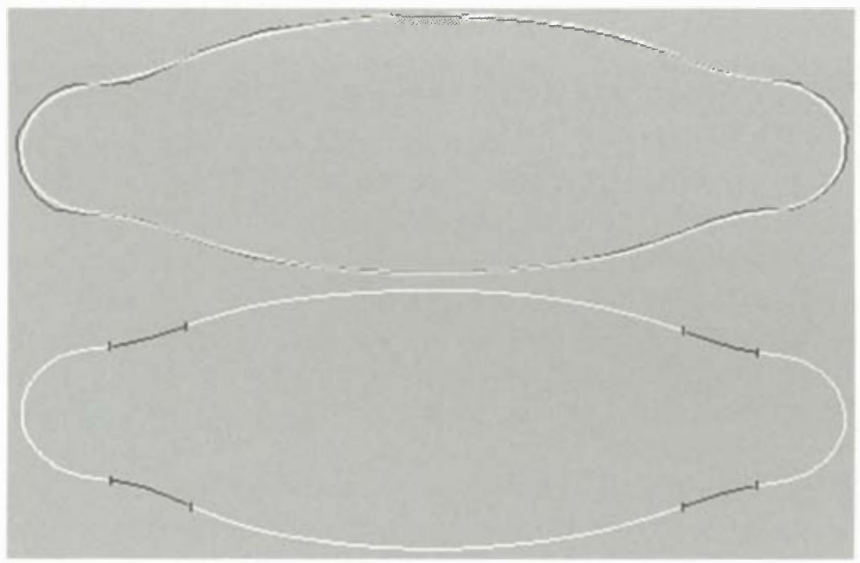

Fig. 2. Contour segment analysis. The upper figure shows the original (single pixel) extracted outline (black) and the filtered outline (white) used for segment analysis. The lower figure shows the subdivision of the filtered outline into concave (black) and convex (white) segments. the slight curvature of the mantle as it approaches the valve face. For image acquisition, all valves were positioned with their long axis parallel to the $x$-axis of the image. A standardized image of background noise was digitally subtracted from each image to remove dust specks from within the microscope and camera (Bayer et al. 2001). For c. 10\% of the valves, minor manual editing of the digital image was needed to separate the outline of the diatom valve from debris or other valves. This involved localized burn-in of pixels to homogenize grey levels along a contour. If the outline was incomplete or obscured, the valve was discarded from the analysis.

SEM was performed with a Zeiss DSM 962 operating at $15 \mathrm{kV}$; specimens were tilted to $15^{\circ} \mathrm{C}$. Negatives from SEM and LM were subsequently digitized and the images manipulated using Adobe Photoshop (www.adobe.com) for publication.

\section{Measurement of characters}

For morphometric analysis of the digital images, characters were extracted from the saved images using Optimas image analysis software. Valve boundaries were defined from the outline focus images using manual thresholding, and a single pixel outline of each diatom was saved as a separate image. From these images, all measurements relating to valve outline were obtained automatically using a customized macro. Characters extracted included valve length, width and rectangularity (area divided by area of the bounding rectangle). Striation density was measured from the images focused on the striae, using another customized Optimas macro. This macro requires interactive definition of a region of interest for measurements, and then it extracts luminance minima (which represent the striae in black-spot focus, i.e. one in which pores show up black against the white of solid silica) from a transect across this region. The regions chosen for measurement of stria density extended from the (apical) margin of the central area towards the poles, immediately alongside the raphe-sternum. Some previous authors (e.g. Anonymous 1975) have recommended measurement near the valve margin. We rejected this 


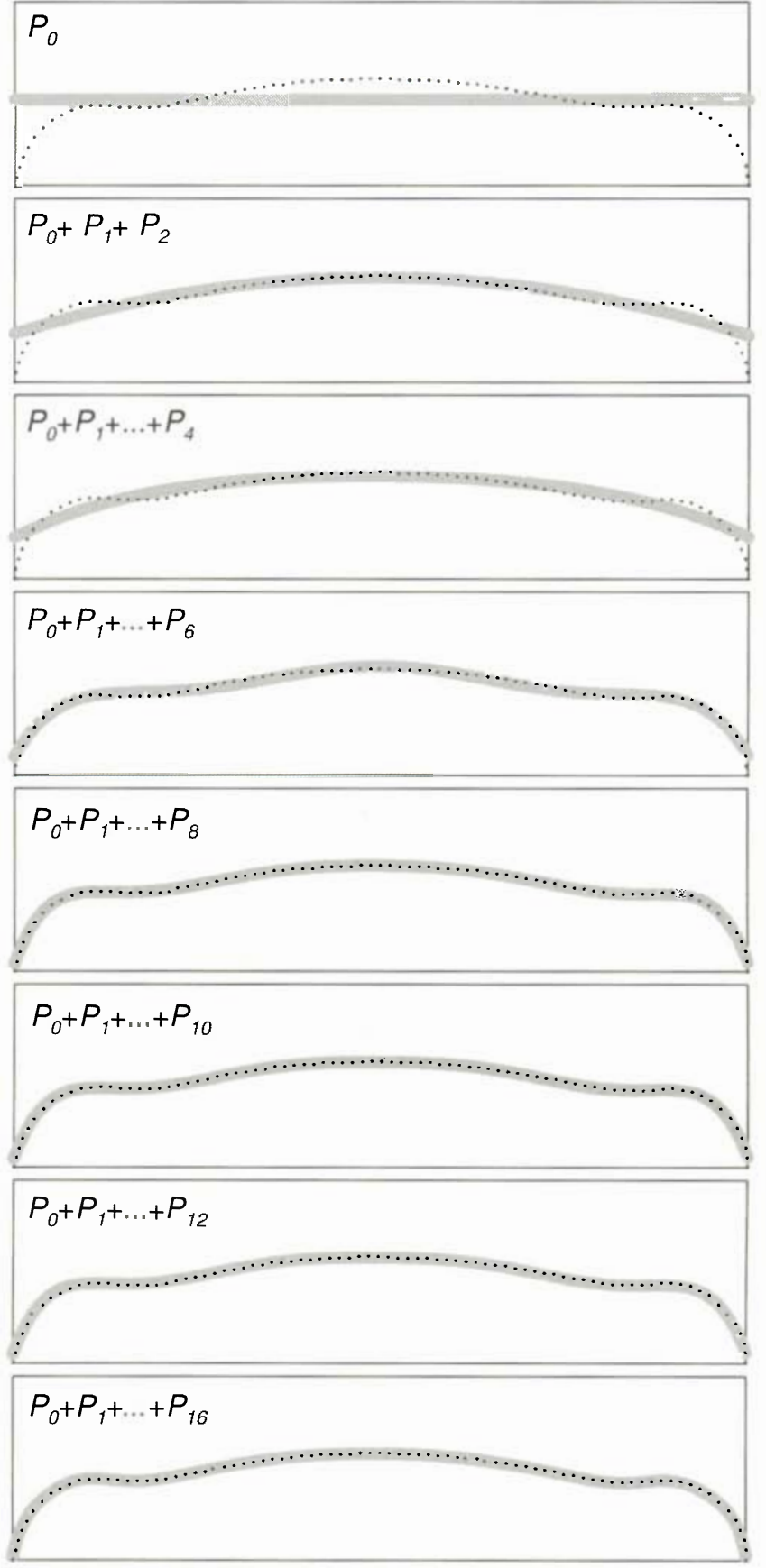

Fig. 3. Legendre polynomials. This figure shows the contribution of different polynomials to the overall shape of the diatom. The continuous grey band is the line given by the polynomials and the dashed line is the shape of the diatom. Each successive polynomial further refines the shape, incorporating more component curves, until the whole shape of the diatom is described (i.e. until the grey and dashed lines match). Note that the last few even polynomials make almost no further contribution to the overall shape: the reconstructed and original shapes match very well by the addition of polynomial $P_{10}$.

because stria formation begins from the raphe-sternum (reviewed by Round et al. 1990) and is more constant here than near the margin, because the striae radiate out, with intercalation of new striae to restore the initial density only when there is enough space (e.g. Figs 1, 4).
Stria angles near the valve centre were measured interactively, at the third stria from the central area (Fig. 1) in the upper right quadrant of the valve: valves were rotated into a horizontal position for imaging, no account being taken of the orientation of the primary side of the valve, so that the quadrant chosen was arbitrary with respect to the fundamental developmental asymmetry of the raphid diatom valve (cf. Round et al. 1990, p. 40, 41). One angular measurement was made for this stria near the raphe and another near the valve margin and a composite measure of striation curvature was then calculated by subtracting the central from the peripheral angle: this summarizes the degree of bend in the striae. The angles of the polar silica bars (Fig. 1) were measured from the bar focus images using a customized macro in Optimas which required the drawing of a line along the bar. The bars were measured in a strict order, top left, top right, bottom left then bottom right. The angles were then standardized to give the deviation from the vertical (see Table 2 for calculation) and the standardized angles were then averaged to give the mean standardized bar angle.

\section{Legendre polynomial shape analysis}

Legendre polynomials were calculated from the single pixel outlines following the method implemented by Ciobanu \& du Buf (2002). Stoermer \& Ladewski's (1982) study of Gomphoneis herculeana (Ehrenberg) Cleve was the first attempt to model the shape of diatom valves by fitting Legendre polynomials in the least-squares sense. We have adapted their method and a description of the procedure is given here [recently, Pappas \& Stoermer (2003) have given a detailed account of a Legendre polynomial study of Cymbella C. Agardh].

Legendre polynomials constitute an orthogonal set of functions and are defined on the interval $[-1,1]$. The entire set can be obtained using the following recurrence relation (Abramowitz \& Stegun 1974):

$$
(n+1) P_{n+1}(x)=(2 n+1) x P_{n}(x)-n P_{n-1}(x),
$$

where $n=1,2, \ldots$ and $P_{0}(x)=1$ and $P_{1}(x)=x$. Some of the resulting polynomials are $P_{2}(x)=\left(3 x^{2}-1\right) / 2, P_{3}(x)=$ $\left(5 x^{3}-3 x\right) / 2$, etc. A partial Legendre polynomial approximation of a function $F$ like

$$
F(x)=\sum_{n=0}^{k} a_{n} P_{n}(x)
$$

can be used to model, for example, the upper half of a valve contour with adequate precision. The coefficients $a_{0}, a_{1}, \ldots$, $a_{k}$ are obtained after a process of fitting and qualify as shape descriptors. In Fig. 3 we present the contribution of successive Legendre polynomials to the approximation of an upper valve contour. To obtain an optimal fit $\left(\chi^{2}<0.01\right.$ : see Press et al. $1999), k=16$ was sufficient in this study.

For shape discrimination purposes, we selected only coefficients $a_{0}, a_{2}, a_{4}, \ldots, a_{16}$ because the odd coefficients $a_{1}, a_{3}$, $\ldots, a_{15}$ (which express asymmetry along the valve, as in e.g. Gomphonema Ehrenberg) had values very close to zero. This is to be expected because Sellaphora valves are basically symmetrical end-to-end. A reviewer has suggested to us that we should nevertheless have included the odd coefficients, to test for subtle asymmetry. However, we saw no possibility of get- 

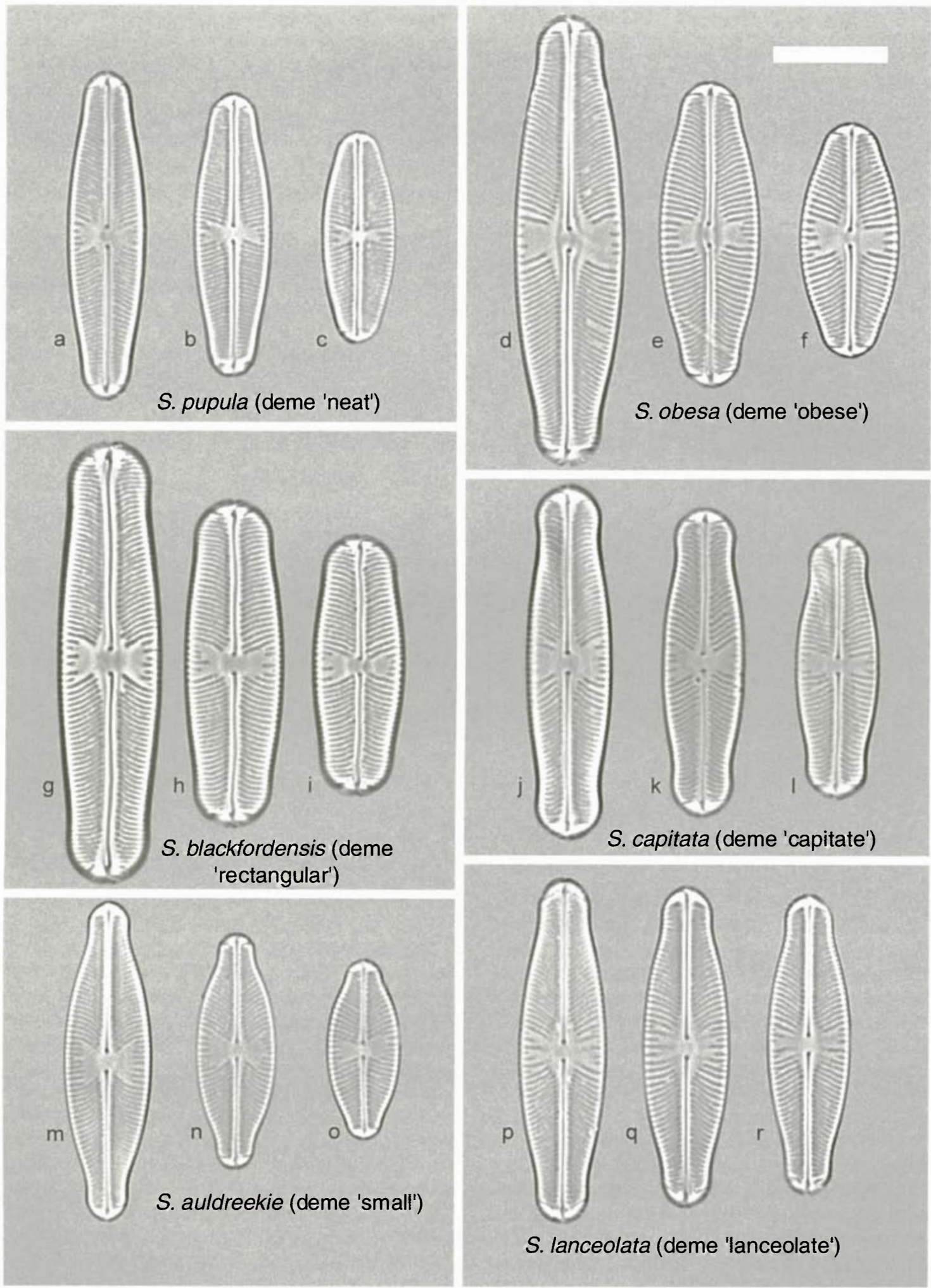

Fig. 4. Six species (demes) of Sellaphora from Blackford Pond. The shortest and longest valves are shown for each species from within the morphometric data set, as well as a valve as near to the mean length as possible, to give an idea of the variation in shape that accompanies size reduction. For all species, except $S$. lanceolata (deme 'lanceolate'), length varies much more than width. The illustrations of $S$. pupula (= the 'neat' deme) are designated epitypes. Scale bar $=10 \mu \mathrm{m}$. 
Table 2. Method for calculating standardized bar angles. The standardization gives the deviation from the axis vertical to the raphe system. The mean is then calculated to give the mean standardized bar angle.

\begin{tabular}{lc}
\hline \multicolumn{1}{c}{ Bar angle } & Calculation \\
\hline Bar angle 1 (top left) & angle $-90^{\circ}$ \\
Bar angle 2 (top right) & $90^{\circ}-$ angle \\
Bar angle 3 (bottom left) & $270^{\circ}-$ angle \\
Bar angle 4 (bottom right) & angle $-270^{\circ}$ \\
\hline
\end{tabular}

' Position when the valve is oriented horizontally.

ting meaningful information from such an analysis because the valves were not, and could not be, oriented consistently in relation to a meaningful landmark (see Measurement of characters, above). In all cases, the valves were presented valve face uppermost, and in most of the demes it is possible to distinguish between the primary and secondary sides of the valve (the valves of all raphid diatoms are asymmetrical in their development, one side - the primary side - being formed before the other: see Round et al. 1990). Hence in these cases, it would have been possible to use the polarity of the developing valve as a 'landmark' to orient valves consistently, e.g. with the primary side towards the top (cf. Fig. 1). However, two factors mitigate against investigation of asymmetry along the apical or transapical axes. One is that in the 'small' deme, it is often difficult or impossible to distinguish between the primary and secondary sides, so that consistent orientation cannot be guaranteed, and the other is that Sellaphora exhibits 'oscillatory behaviour' at successive cell divisions, the orientation of the development of the new valves at one cell division being opposite that of the new valves at the last division. Hence the orientation of the primary and secondary sides relative to the outline in any one valve has no biological significance, in contrast to the situation in diatoms like Cymbella and Gomphonema, where the orientation of development remains constant (Mann \& Stickle 1988; Round et al. 1990). We conclude, therefore, that using the odd coefficients only adds noise.

The first step in the implementation consisted of normalizing the contour by a uniform scaling in $x$ and $y$. The contours were already oriented horizontally, so the extreme left and right contour points were detected and the middle of the line segment through these two points taken as the origin of a new Cartesian system. All the coordinates of the contour points were recalculated relative to this system. Half the length of the above mentioned line segment was used to normalize the contour points, i.e. they are all inside the unit square $[-1 \leq$ $x, y \leq \mathrm{I}]$ and the two extremes of the valve apical axis assume the coordinates $(-1,0)$ and $(1,0)$. These two points are the start and the end of two curves, the upper part and the lower part of the valve contour.

Next, 60 equidistant points were selected on each of the upper and lower curves and these were used for the two Legendre approximations. We used Numerical Recipes' (Press et al. 1999) singular value decomposition. The main routine is $s v d f i t$, which calls the $s v d c m p$ and $s v d k s b$ routines, and the Legendre polynomial values are generated by the fleg routine. The output from this procedure comprised 18 Legendre coefficients, the first nine of which describe the upper half of the contour and are the coefficients of the even numbered
Legendre polynomials $P_{0}, P_{2}, P_{4}, P_{6}, P_{8}, P_{10}, P_{12}, P_{14}$ and $P_{16}$; the second nine were the corresponding polynomials for the lower half of the contour. All the taxa used in this study were bilaterally symmetrical, and so only the first nine coefficients, describing the upper half of the contour, were inspected (an additional reason for this being the lack of consistent orientation of the outline with respect to the primary-secondary polarity, discussed above). PCA was carried out using both the first six and the first nine even coefficients, using the correlation matrix. The coefficients of $P_{12}, P_{14}$ and $P_{16}$ did not appear to contribute significant additional information on diatom shape relevant to separation of the demes (visual inspection suggests that a very good match to valve outline is achieved by use of $P_{0}-P_{8}$ : Fig. 3), but they were included nevertheless because it might otherwise have been argued that we had thrown away subtle but important information. PCA was carried out and graphs prepared using SigmaPlot, version 8.02 (SPSS, Chicago, IL, USA).

\section{Segment shape analysis}

The single pixel outlines were also analysed using a new method for shape quantification developed during the ADIAC project (du Buf et al. 1999; du Buf \& Bayer 2002). A summary of this method is given below [for a complete explanation see Loke \& du Buf (2002)].

It is assumed that a contour is sampled clockwise and consists of a fixed number of points. In order to reduce quantization noise and to make feature extraction scale-invariant, the $x$ and $y$ coordinates of all contour points are filtered using a small Gaussian kernel [Loke \& du Buf (2002); Fig. 2 shows an example]. The local shape is deformed somewhat by the filter, but this will apply to all contours in a systematic way. The contour feature extraction starts with computation of the convexity-concavity $C$ and the curvature $\theta$ for all contour points. For each point $P_{i}$ on the contour these are computed by:

$$
\begin{aligned}
C_{i} & =\frac{1}{m_{1}} \sum_{j=1}^{m_{1}} \overrightarrow{P_{i-j} P_{i}} \times \overrightarrow{P_{i} P_{i+j}} \text { and } \\
\theta_{i} & =\frac{1}{m_{2}} \sum_{j=1}^{m_{2}} \arccos \frac{\overrightarrow{P_{i-j} P_{i}} \cdot \overrightarrow{P_{i} P_{i+j}}}{\left|\overrightarrow{P_{i-j} P_{i}}\right|\left|\overrightarrow{P_{i} P_{i+j}}\right|}
\end{aligned}
$$

with $m_{1}$ and $m_{2}$ being mask sizes, $\times$ the vector crossproduct, the vector inproduct, and $\left|\overrightarrow{P_{a} P_{b}}\right|$ the length of vector $\overrightarrow{P_{a} P_{b}}$ (Dong \& Hillman 2001). These equations allow the computation of the convexity-concavity and curvature for all contour points. Figure 2 summarizes the convexity-concavity computed at all points for one contour, by depicting negative values of $C$ (concave) as black and positive values (convex) as white.

Applying Eqs 1 and 2 at each contour point results in a very large feature set. This set must be compressed to give global contour features that determine the entire shape. This can be done in three ways. The first is simply to determine the mean, maximum and minimum curvature $(\mathrm{cm}, \mathrm{cx}$ and $\mathrm{cn})$ of all points on the contour. The second is to partition the contour into convex and concave segments, compute features for each segment and determine the mean, maximum and minimum of each segment feature. Specifically, the contour is 
partitioned into convex and concave segments by grouping together all adjacent points on the contour that are convex or concave. For example, in Fig. 2 (bottom), this yields eight segments. This grouping allows the calculation, for each part of the segmented contour, of the mean $(m)$, maximum $(x)$ and minimum $(n)$ curvature from all contour points in that segment, as well as the length $(l)$ of the segment, yielding a total of four features for each contour segment. Thereafter, the following global contour features are calculated: $m m, x m, n m$, $m x, x x, n x, m n, x n, n n, m l, x l, n l$, being the mean, maximum and minimum of all mean segment curvatures, the mean, maximum and minimum of all maximum segment curvatures, etc.

The third method of computing global contour features is to perform a symmetry (similarity) analysis (Loke \& du Buf 2002) after the contour segmentation. In this case, instead of treating each segmented part independently of all other parts, those segments that can be regarded as equivalent on the basis of computed features ('elementary segments') are grouped and the means of their mean, maximum and minimum curvatures and of their lengths are calculated. This improves the stability of the analysis. Hence, averaging $m, x, n$ and $l$ for each elementary segment yields an elementary segment mean, maximum and minimum curvature ( $M, X$ and $N$, respectively) and an elementary length $(L)$. Thereafter, global contour features are again computed, but now using $M, X, N$ and $L$ instead of $m, x, n$ and $l$. These features are denoted as $m M, x M, n M$, $m X, x X, n X, m N, x N, n N, m L, x L, n L$. Note that if a contour is completely convex, it will have only one segment. In this case, the maximum contour curvature equals the maximum (elementary) segment curvature, i.e. $c x=x x=x X$. However, if a contour consists of different parts, this will not be the case.

To summarize, we calculated the curvature at all contour points, divided the contour into segments on the basis of the convexity-concavity and performed symmetry analysis to identify equivalent segments. These procedures gave three sets of features: point, segment and elementary-segment features. Then, by taking the mean, maximum and minimum for each of these features, global contour features were obtained.

\section{Taxonomy and terminology}

Mann (2001) reinvestigated the type material of $S$. pupula, amended the lectotype ('second-step lectotypification') to be a single valve only (on BM slide 17918), and concluded that $S$. pupula sensu stricto is conspecific with the 'neat' deme. In order to make the application of the epithet pupula name even more certain, we designate here the photographs of Blackford Pond 'neat' as epitypes. The other five demes are described here as new species within Sellaphora, based on evidence from the morphometric analysis (see above) and data in previous papers (Mann 1989a; Mann et al. 1999). In order to minimize ambiguity, we use verbal characterizations of shape, stria pattern, raphe morphology and other features, as seen in LM, that follow Barber \& Haworth (1981) wherever possible, because their descriptive terminology is made explicit by diagrams. This has the disadvantage that our descriptions differ a little from those of $S$. pupula by e.g. Hustedt (1927-1966, 1930) or Krammer \& Lange-Bertalot (1986). However, work carried out as part of the Prometheus projects (Pullan et al. 2000; Raguenaud et al. 2002; S.M. McDonald, C. Raguenaud,
M.R. Pullan, J.B. Kennedy, G. Russell \& M.F. Watson at http: //www.dcs.napier.ac.uk/ prometheus/home.html) has highlighted the need for clearly defined taxon concepts. Given the possibility of several more near-cryptic species within $S$. pup$u l a$, it is important to be clear about the limits of the new species described here, in order to avoid creating further taxonomic problems. These species present a further difficulty in that the differences between them are not immediately obvious and it is hoped that, by giving clear references to the diagrams in Barber \& Haworth (1981) as well as by using quantitative characters, confusion will be avoided. Other terminology follows Ross et al. (1979), Mann (1981) and Round et al. (1990).

\section{Data availability}

One purpose in making the analyses reported here, apart from exploring variation in $S$. pupula from Blackford Pond, was to establish a baseline data set that can be used as a comparator for future morphometric analyses of the $S$. pupula complex. We are therefore making the digital images and extracted outlines available, together with tables of all data, at http:// rbg-web2.rbge.org.uk/algae/research/research.htm. This site also includes photographs of the holotypes of the five new species and the epitype and lectotype of $S$. pupula, each presented as a 'focus stack', which can be explored interactively via a focus bar or short movie clip. In addition, so that types can be located more easily, we have included (on the web pages) low-magnification photographs of the context of the five holotypes and the lectotype and one of the epitypes of $S$. pupula.

\section{RESULTS AND DISCUSSION}

\section{Morphology}

All the demes have the characteristic features of the $S$. pupula complex, i.e. silica bars at the poles [separating $S$. pupula from e.g. S. laevissima (Kützing) D.G. Mann] and a large transversely expanded central area of variable shape [separating S. pupula from S. bacillum (Ehrenberg) D.G. Mann, which has a smaller, rounded central area] (Hustedt 1927-1966; Krammer \& Lange-Bertalot 1986). Cells are solitary and motile and generally live in the epipelon.

Visual inspection of valves of $S$. pupula from Blackford Pond collected before 1990 indicates the presence of six demes (Figs 4, 17-22), varying in size (see below) and shape (see also Mann 1984, 1989a); a seventh deme has been present in more recent samples, but this is not treated here. Two demes, 'capitate' and 'rectangular', have valves that, using the descriptive terminology of e.g. Hustedt (1927-1966, 1930), are almost linear, with broadly capitate or subcapitate apices (Figs 4g-1, 19, 20). The other demes all have more strongly tapered valves, with slightly ('neat' and 'obese': Figs $4 \mathrm{a}-\mathrm{f}$, 17,18 ) or more strongly ('small' and 'lanceolate': Figs $4 \mathrm{~m}-$ $r, 21,22$ ) rostrate apices. As is common, though not universal, in pennate diatoms (Geitler 1932), valve shape becomes simpler during the life cycle, as size reduces, with progressive loss of capitate or rostrate apices (e.g. compare Fig. $4 \mathrm{~m}$ with o).

The demes differ in the robustness of their valves. We have 

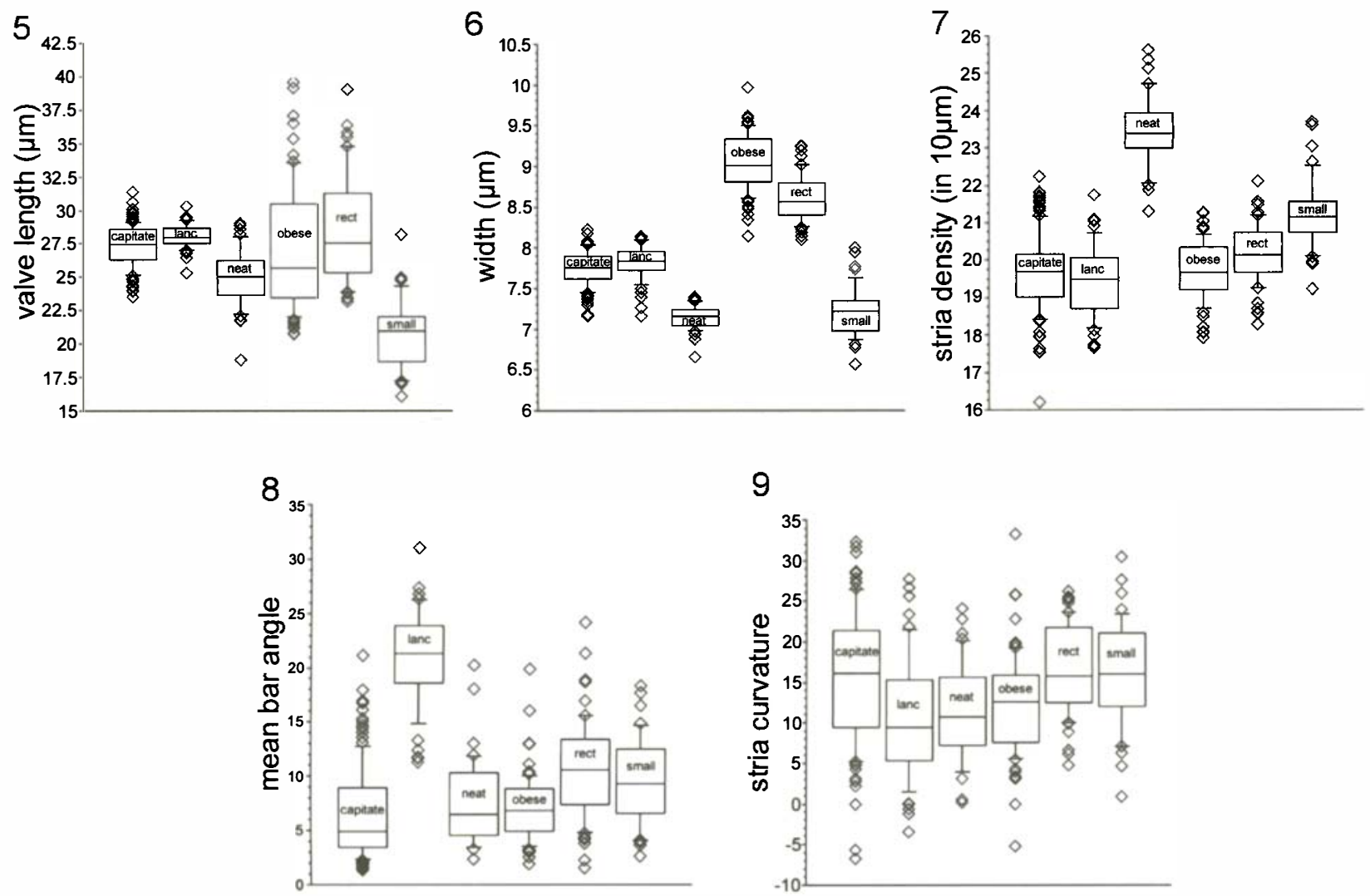

Figs 5-9. Box plots of morphometric data. Boxes include the 25th and 75th percentiles (the horizontal line is the median); bars above and below include the 10th and 90th percentiles, and individual points are given beyond the bars. Deme names are given inside the boxes: capitate, deme 'capitate' (Sellaphora capitata); lanc, deme 'lanceolate' ( $S$. lanceolata); neat, deme 'neat' ( $S$. pupula); obese, deme 'obese' $(S$. obesa); rect, deme 'rectangular' (S. blackfordensis); small, deme 'small' (S. auldreekie).

Fig. 5. Length. 'Obese' and 'rectangular' have the longest valves within the data set analysed.

Fig. 6. Width. 'Obese' is the widest and 'small' and 'neat' the narrowest.

Fig. 7. Stria density. 'Neat' has the most dense striation pattern.

Fig. 8. Mean bar angle. 'Lanceolate' has the most strongly angled bars.

Fig. 9. Stria curvature. There is little difference between the demes in terms of how angled the striae are.

not been able to quantify this, but it can be gauged to some extent from the darkness of the outlines in Fig. 4 (most of these, and all of the 'rectangular' specimens, are single valves, lacking accompanying girdle bands). The deme with the smallest valves ('small': Fig. $4 \mathrm{~m}-\mathrm{O}$ ) is also the most delicate. The most heavily silicified is 'rectangular' (Fig. 4g-i).

All demes have a narrow axial area (Figs 4, 17-22). The raphe of 'rectangular' is noticeably sinuous but otherwise no differences in raphe structure are visible in LM. The central raphe endings are slightly expanded and deflected towards the primary side of the valve (Round et al. 1990, pp. 41, 42); the terminal fissures can be seen only with some difficulty and bend towards the secondary side (e.g. Fig. 1). The central area varies in shape between demes. In 'small' it is well defined and shaped like a bow-tie (Figs $4 \mathrm{~m}-\mathrm{o}, 21$ ). The central area is also shaped like a bow-tie in 'rectangular', 'capitate', 'obese' and 'neat', but its outline is more irregular than in 'small' (Figs 4a-1, 17-20), and in smaller valves, particularly of 'neat' and 'obese', it can become almost rectangular. The most divergent morphology is in 'lanceolate', where the central area is more elliptical and invaded by 'ghost striae' (Figs 1, 4p-r, 22), which are faint inward extensions of the striae that do not contain poroids (see also Figs 49, 51). They rep- resent shallow indentations in the internal (Fig. 51) and apparently also in the external surface of the central area (Fig. 49).

Ultrastructural features of the valve are described in the accounts of each deme. The fundamental structure of the valve varies little and was described by Mann (1989b). In the Blackford demes, the striae appear in LM as thin unbroken lines: individual pores cannot be distinguished. SEM reveals that the striae are in all cases uniseriate and contain small round poroids (Figs 23-52); the striae are separated by rounded ribs. The areolae are occluded internally by domed hymenes (sieve membranes) (Figs 41, 42: in other valves illustrated, the hymenes have dissolved). The raphe-sternum shows some variation in its external development, sometimes being almost plain (Figs 44, 45, 49, 50), but elsewhere being somewhat elevated and clearly separated from the remainder of the valve face by shallow grooves along part or the whole of the valve (Figs 29, 34, 35). The terminal fissures show subtle differences between demes (compare Figs 30,40 ), and can be smoothly curved (Fig. 30) or inflected (Fig. 40) or complex (Fig. 35), but internally the raphe morphology is constant. Chloroplast morphology and cell structure are uniform throughout and have been described in detail by Mann (1985, 1989b). Girdle 
10

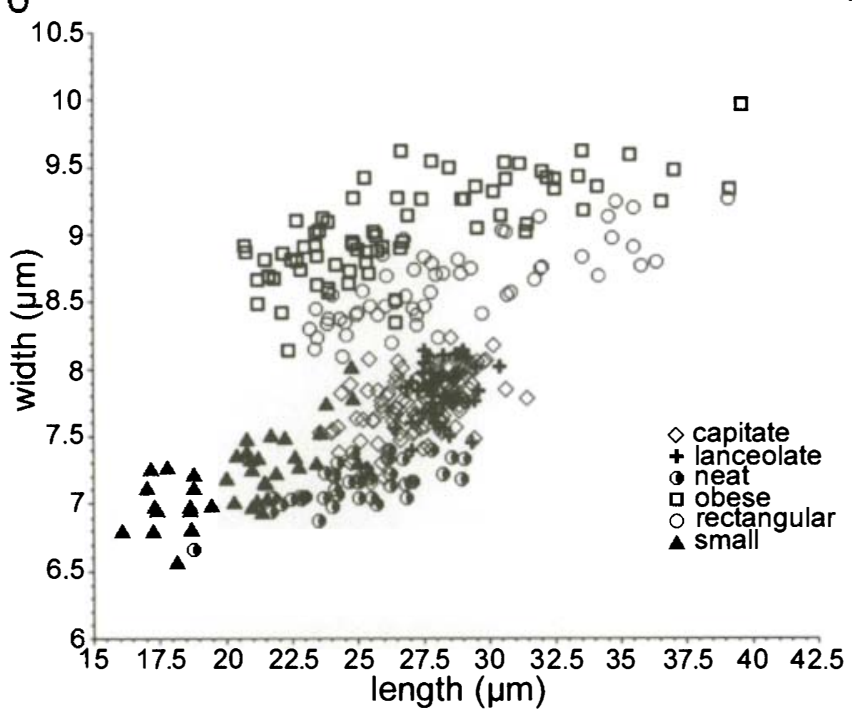

11

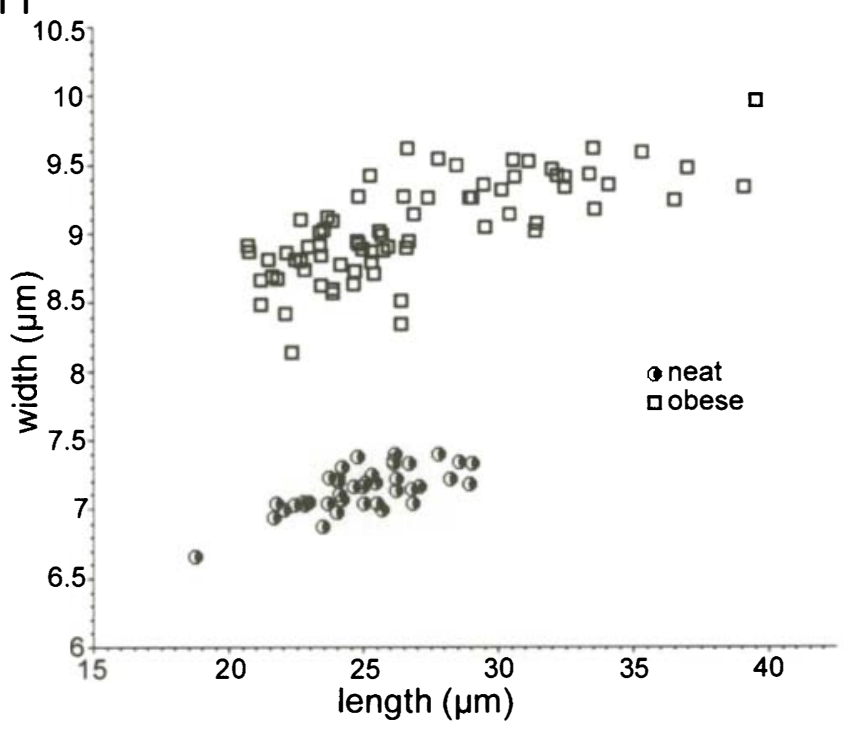

12

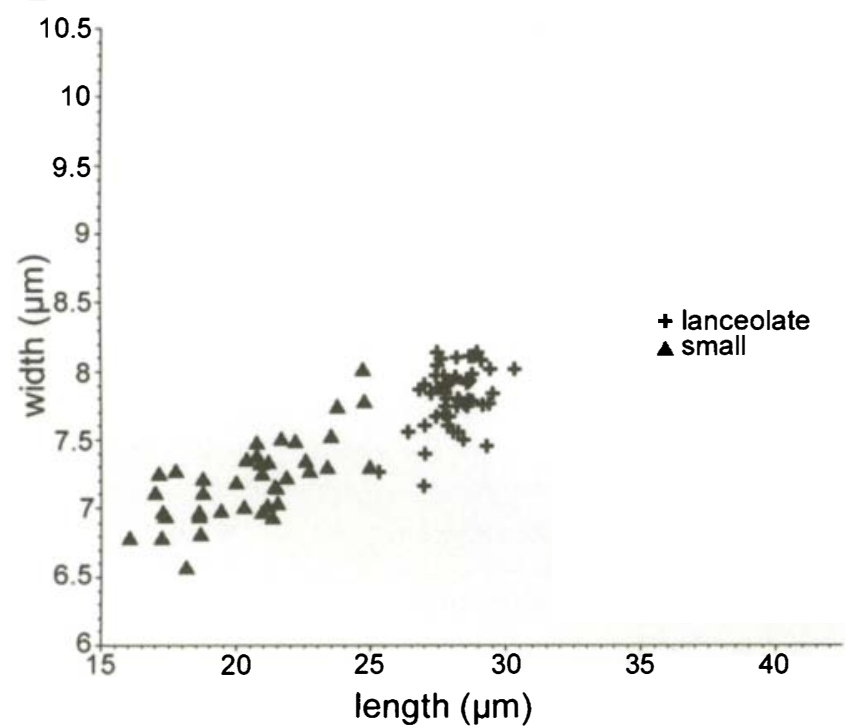

13

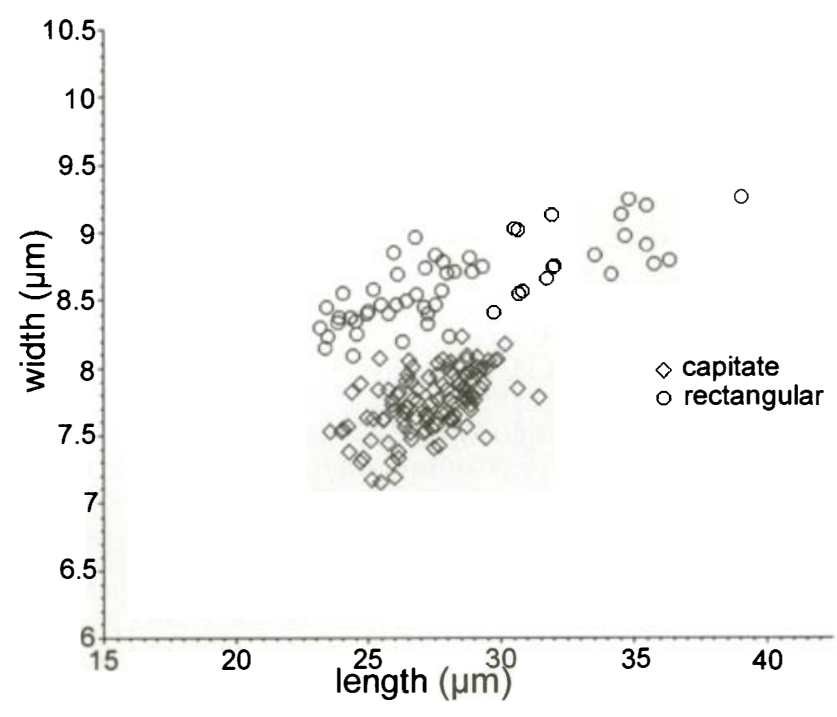

Figs 10-13. Length vs width. These characters are traditionally used to distinguish diatom species. Fig. 10 shows all demes together, illustrating their overlapping ranges of size [this in part explains the traditional reluctance (e.g. Krammer \& Lange-Bertalot 1986) to separate the demes taxonomically]. However, in Figs 11-13, with the demes separated out, size trajectories can be seen. Demes 'neat' and 'obese' (Sellaphora pupula and $S$. obesa), although very similar in shape and hard to distinguish from each other, occupy different size trajectories with 'obese' being consistently wider for any given length (Fig. 11). Fig. 12 shows 'small' and 'lanceolate' (S. auldreekie and S. lanceolata), with 'lanceolate' showing a tight cluster rather than a trajectory in length-width space. Fig. 13 shows that, for any given length, 'rectangular' (S. blackfordensis) is wider than 'capitate' ( $S$. capitata), despite their superficial similarities.

structure has not been studied in all demes, but there appears to be no significant variation between those that have been studied (see Mann 1989b).

\section{Morphometric analysis}

SINGLE CHARACTERS: Previous studies (Mann 1984, 1989a, 1999; Mann et al. 1999) have shown that five of the six demes are capable of auxosporulation and hence also have a size reduction cycle. It is therefore unsurprising that length varies widely within the morphometric data set (Fig. 5; such box plots have been used previously by Droop 1994; Droop et al. 2000). However, one noticeable exception is the very low variation between 'lanceolate' valves, which agrees with previous observations (Mann 1989a): during 20 years of observations, no significantly smaller or larger valves have been observed than those represented in Fig. 5, and no sexual reproduction has been observed. By contrast, the relatively low length variation in 'capitate' shown in Fig. 5 is an artefact of the particular samples that were suitable for morphometric analysis, as shown by the more extensive life cycle data provided by Mann et al. (1999). There is substantial overlap between the 


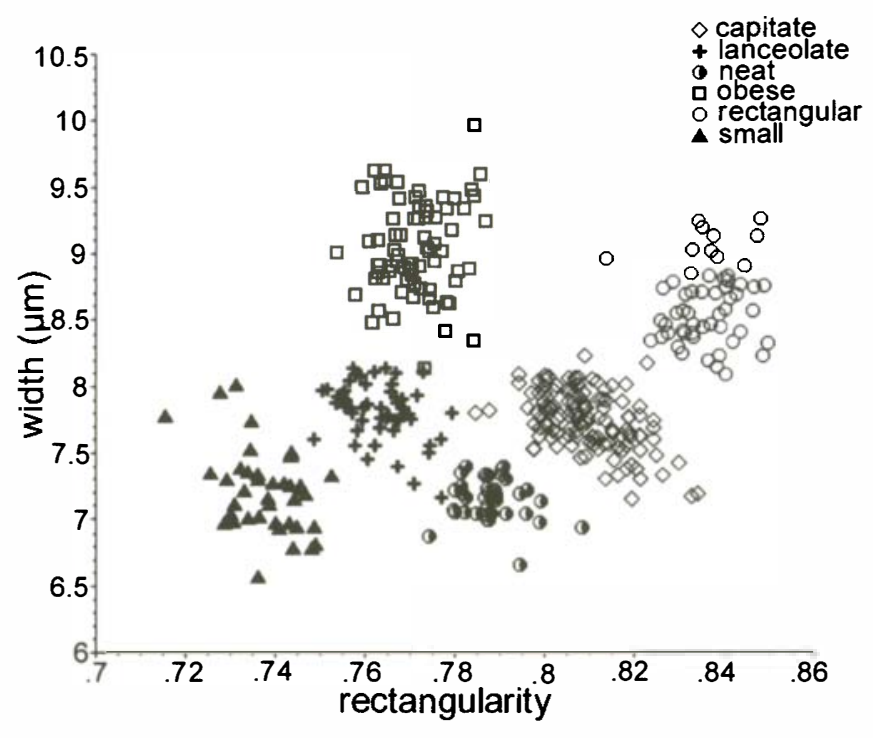

Fig. 14. Rectangularity vs width. This plot shows six fairly distinct clusters corresponding to the six demes within Sellaphora pupula.

length ranges of the six demes, but 'small' is generally shorter. Valve width varies much less than length, both in absolute terms and proportionately (Fig. 6).

Stria densities for all the demes except 'neat' cluster around 19-21 in $10 \mu \mathrm{m}$ (Fig. 7), 'neat' being more densely striate, with a mean of $c .23 .5$ in $10 \mu \mathrm{m}$. The striae are radial at the centre but become parallel or slightly convergent towards the poles; the tendency towards convergence is most strongly developed in 'lanceolate' (Figs 4, 17-22) and this is reflected also in the correlated character of mean bar angle (Fig. 8). The striae are mostly slightly curved (Figs 4, 17-22), and visual inspection suggested that there might be a difference between 'neat', where the striae seem to be straight, and 'rectangular' or 'capitate', where the striae appear more curved. However, although curvature measurements (Fig. 9) do show such a trend, the differences between demes are small and there is almost complete overlap between them [other demes, not present in Blackford Pond, appear to differ more in this respect: see Mann \& Droop (1996, figs 28-30)]. Near the poles, in those demes and valves with convergent striae (particularly 'lanceolate' and large 'obese' valves), some striae are usually sharply angled (geniculate), which leads to truncation of some striae subtended by the raphe (Fig. 1, 'short striae'; Figs 4d, p-r, 22).

BIVARIATE ANALYSIS: In some cases of semicryptic speciation in diatoms [e.g. the 'major' and 'minor' demes of $\mathrm{Nei}$ dium ampliatum (Ehrenberg) Krammer: Mann (1988a, 1989a, 1999)], although there is considerable overlap in the ranges of length and width when taken separately, length vs width plots reveal no bivariate overlap between demes. By contrast, a length vs width plot for all demes of $S$. pupula (Fig. 10) does not show a clear separation between them: there is considerable overlap between the 'lanceolate' and 'capitate' demes and larger valves of 'small' attain the same aspect ratio as some 'lanceolate' (Fig. 12). However, the length-width plots do reveal a very clear separation between 'neat' and 'obese' (Fig. 11) and between 'capitate' and 'rectangular'
(Fig. 13), which are pairs of demes that differ very little in shape and striation pattern.

SHAPE ANALYSIS: Figures 14-16 explore shape variation among the six demes in three different ways. Figure 14 uses a relatively crude shape measure - rectangularity - and explores how this covaries with valve width. The biplot shows six clusters, which correspond to the initial visual classification of specimens into demes. The clusters do not overlap, although they touch in a few cases (e.g. 'lanceolate' with 'neat' or 'capitate'). However, this separation is achieved only by including size as a variable. The shape measure itself does not fully discriminate between demes, showing overlaps between many demes.

A PCA of the Legendre coefficients did not separate 'capitate' from 'rectangular', or 'obese', 'neat' and 'lanceolate' from each other. In Fig. 15, we show a plot of PCl vs PC2 (Fig. 15a) for a PCA of data for the first nine even Legendre coefficients. We also show projections of two three-dimensional plots, of PC2 vs PC3 vs PC6 (Fig. 15b) and $\mathrm{PCl}$ vs PC2 vs PC3 (Fig. 15c), oriented to give the maximum visual separation of 'rectangular' and 'capitate' and of 'neat', 'obese' and 'lanceolate', respectively. Table 3 gives summary statistics for the PCA and shows, as expected, that PC1 $(42.1 \%$ of total variance) is strongly associated with $P_{6}$ (expressing the tendency towards a triundulate outline - given by the rostrate or subcapitate poles and expanded body of the cell), which otherwise contributes little to the PCs.

We also explored the Legendre data set using various other combinations of Legendre descriptors. Although the analysis identified shape groups, six clearly defined clusters are not seen, regardless of the combinations of Legendre descriptors and PCs used for analysis and display. There was a marginal improvement in the visual separation of demes when the number of Legendre descriptors was reduced to the first six even coefficients $\left(P_{0}, P_{2}, P_{4}, P_{6}, P_{8}\right.$, and $\left.P_{10}\right)$, but there was still an overlap between clusters, as in Fig. 15, and we were unable to find any clearer discontinuities between 'capitate' and 'rectangular', or between 'neat', 'obese' and 'lanceolate' than in Fig. 15b, c. Overall, the Legendre analysis reveals just three elongate clusters (Fig. 15a), which agrees with the impression gained from simple visual comparisons, that there are three basic shapes. Using traditional terminology, as in Hustedt (1927-1966, 1930) and Krammer \& Lange-Bertalot (1986), these could be described as: (1) linear-lanceolate with subcapitate apices (in 'rectangular' and 'capitate'); (2) lanceolate with slightly rostrate apices (in 'obese', 'lanceolate' and 'neat'); and (3) lanceolate with strongly rostrate, narrow apices (in 'small'). Figure 15 demonstrates that there is some tendency towards segregation of the individual demes within shape groups (1) and (2), but there is considerable overlap, producing a continuous distribution in PC space. If there had been no other information available, about other aspects of morphology or about reproductive isolation, it is doubtful whether Legendre analysis would have prompted the hypothesis of six species within Blackford Pond.

By contrast, contour segment analysis shows a clear separation into six clusters, corresponding to the demes distinguished visually, and just two of the variables are required to separate all six demes from each other almost completely in a scatter-plot (Fig. 16): the six well-defined clusters would be 

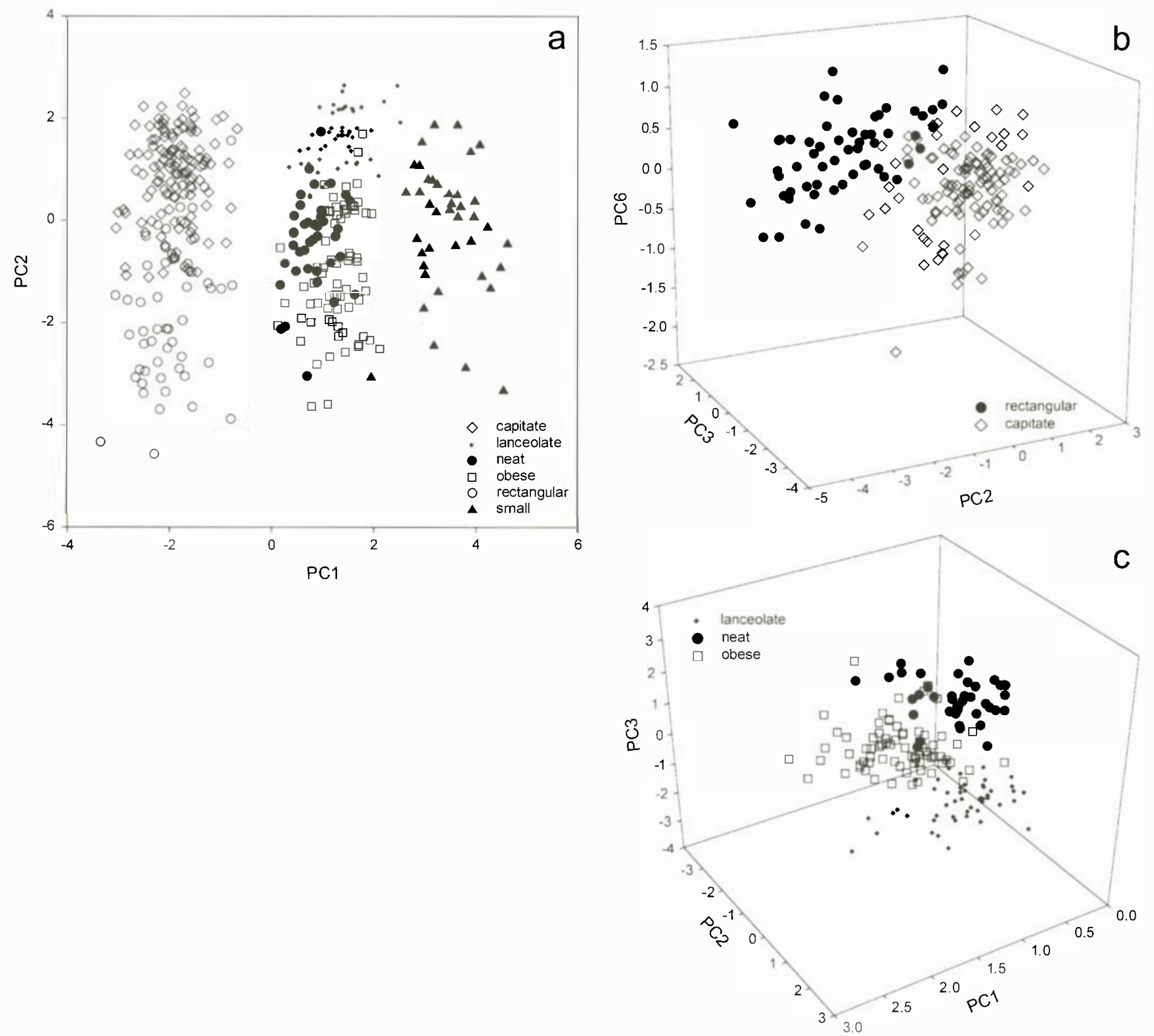

Fig. 15. Legendre polynomial shape analysis: a two-dimensional plot and two three-dimensional plots of a PCA analysis ( 383 valves), using the first nine even Legendre polynomials $\left(P_{0}, P_{2}, P_{4}, P_{6}, P_{8}, P_{10}, P_{12}, P_{14}, P_{16}\right)$. Fig. 15a: PC1 vs PC2 reveals three clusters, which correspond to the three basic shape types within the six demes. The cluster to the left of the plot corresponds to demes 'capitate' and 'rectangular' ( $S$. capitata, S. blackfordensis), which are both linear; the middle cluster comprises demes 'lanceolate', 'obese' and 'neat' (S. lanceolata, S. obesa, $S$. pupula), which are all elliptical-rostrate; and the right cluster corresponds to the 'small' deme (S. auldreekie), which is elliptical, with very narrow poles compared to the central area. Fig. 15b, c show plots of other PCs, orientated to show maximum separation of the 'capitate' and 'rectangular' demes and the 'lanceolate', 'obese' and 'neat' demes, respectively. The clusters overlap in these and other PC plots and no reorientations of the PC plots eliminate this.

readily recognizable in the absence of any a priori classification. The variables used here were $x n$ (the maximum of segment curvature minima) and $c x$ (the maximum curvature value of all individual contour points).

There are two important features of the contour segment plot. First, there is no convincing sign of heterogeneity within any of the demes, so that there is no indication from this aspect of morphology that the $S$. pupula complex in Blackford Pond would be underclassified if it were separated into six segregate species; this is also evident from the rectangularitywidth and Legendre plots. Second, contour segment analysis produces a clear separation between 'capitate' and 'rectangular' and between 'neat' and 'obese'. This is surprising (note that rectangularity on its own does not separate these two pairs: Fig. 14) because the members of each pair look very alike in shape (e.g. compare Fig. $4 b$ with d, g with k) and we cannot formulate any verbal, nonnumerical description to allow identification on shape alone. Thus, whereas 'capitate' valves are often noticeably more constricted near the poles (more capitate) than those of 'rectangular' (Fig. $4 \mathrm{j}-1$, contrast $\mathrm{g}-\mathrm{i})$, individual valves can be difficult to assign correctly without measurement, and during routine identification in the 


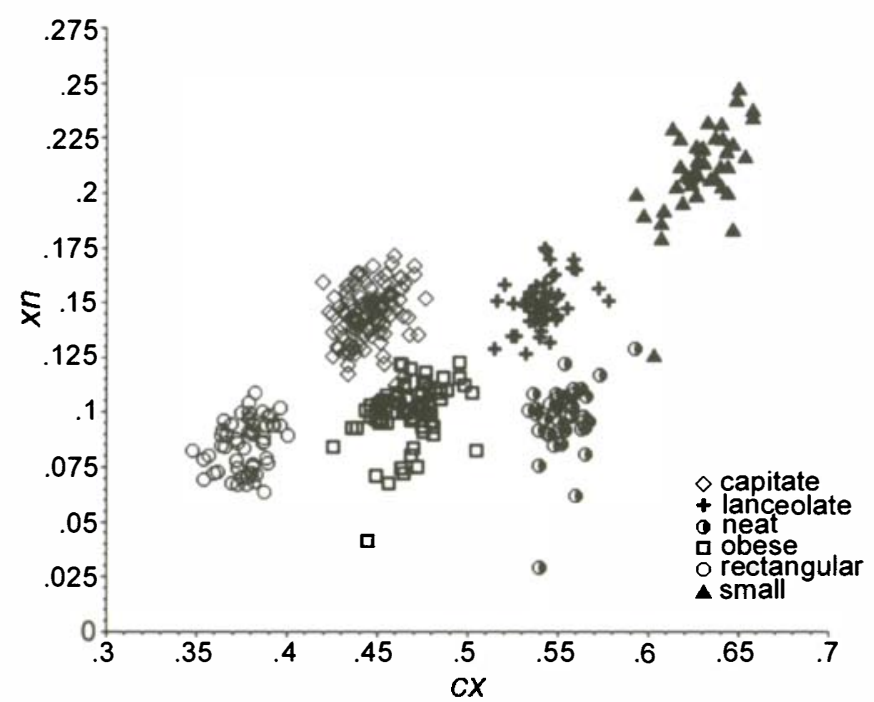

Fig. 16. Contour segment analysis: maximum curvature of all contour points $(c x)$ plotted against the maximum of all segment minimum curvatures $(x n)$, giving six clusters corresponding to the six demes of S. pupula.

light microscope, it is valve size (particularly width) that is most useful in discriminating between these demes. Contour segment analysis is thus a highly sensitive method, revealing aspects of shape variation virtually undetectable to the human eye. Legendre analysis, by contrast, is suitable for discriminating between the major shape groups in the Blackford Sellaphora data-set, but it fails to separate shapes that are clearly differentiated by the contour segment analysis.

\section{Growth, sexual reproduction and reproductive isolation}

During this study we did not succeed in growing 'neat' and 'lanceolate' in culture, nor did we make quantitative estimates of growth rate. However, the four demes we have had in culture are not equally easy to grow and they grow at different rates [at $15^{\circ} \mathrm{C}$ or $20^{\circ} \mathrm{C}$ and in a variety of different daylengths and light intensities, in WC medium (Guillard \& Lorenzen 1972)]. Broadly, 'capitate' and 'small' grow more rapidly than 'rectangular', but cultures of all three are easily established by direct isolation using a micropipette, or by streaking on agar, followed by transfer to liquid medium. 'Obese' is much more difficult to establish in culture and grows more slowly, at perhaps half the rate of 'rectangular'.

Auxosporulation has been observed in all demes except 'lanceolate'. The demes 'capitate', 'rectangular', 'small' and 'obese' are all allogamous (Mann 1984, 1989a, b, 1999; Mann et al. 1999) and the mating system has been studied intensively in 'capitate', 'rectangular' and 'small' (Mann et al. 1999; V.A. Chepurnov \& D.G. Mann, unpublished observations). The pattern of allogamous sexual reproduction is the same throughout, each gametangium producing a single functional gamete and a small apochlorotic supernumerary (residual) cell (Mann 1989b). Although the gametes produced by paired gametangia are alike, there is a physiological differentiation between them, one gametangium (the 'male') producing an active gamete, the other ('female') producing a passive gamete. The zygote is therefore formed within the frustule of the female gametangium. A full account of sexual reproduction is given by Mann (1989b). The mating system varies between the allogamous Blackford demes and brief summaries are given in the descriptions of each species.

'Neat' may be autogamous or apomictic (Mann 1989a) and 'lanceolate' appears to be asexual. If so, the gene pools of these two demes are by definition separated from those of all other demes. For the allogamous demes, information about reproductive isolation is available from two sources: observations of sexualized mixed seminatural populations during $c$. 10 years (particularly 1987-1989: data summarized by Mann et al. 1999, table 1; see also Mann 1984, 1989a, 1999), and laboratory crosses using clonal cultures (Mann et al. 1999; V.A. Chepurnov \& D.G. Mann, unpublished observations for 'capitate', 'rectangular' and 'small'). All available information
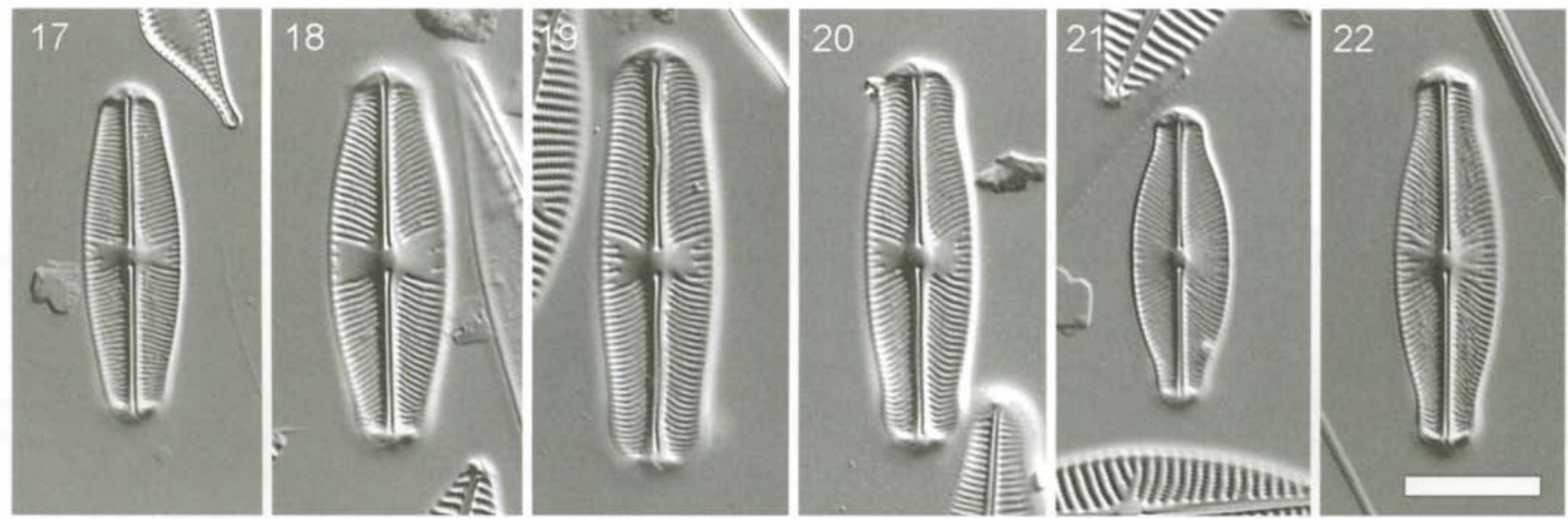

Figs 17-22. Type specimens of segregate species of the Sellaphora pupula complex (cf. Fig. 4), DIC. Scale bar $=10 \mu \mathrm{m}$.

Fig. 17. Sellaphora pupula (Blackford deme 'neat'), epitype.

Fig. 18. Sellaphora obesa (Blackford deme 'obese'), holotype.

Fig. 19. Sellaphora blackfordensis (Blackford deme 'rectangular'), holotype.

Fig. 20. Sellaphora capitata (Blackford deme 'capitate'), holotype.

Fig. 21. Sellaphora auldreekie (Blackford deme 'small'), holotype.

Fig. 22. Sellaphora lanceolata (Blackford deme 'lanceolate'), holotype. 

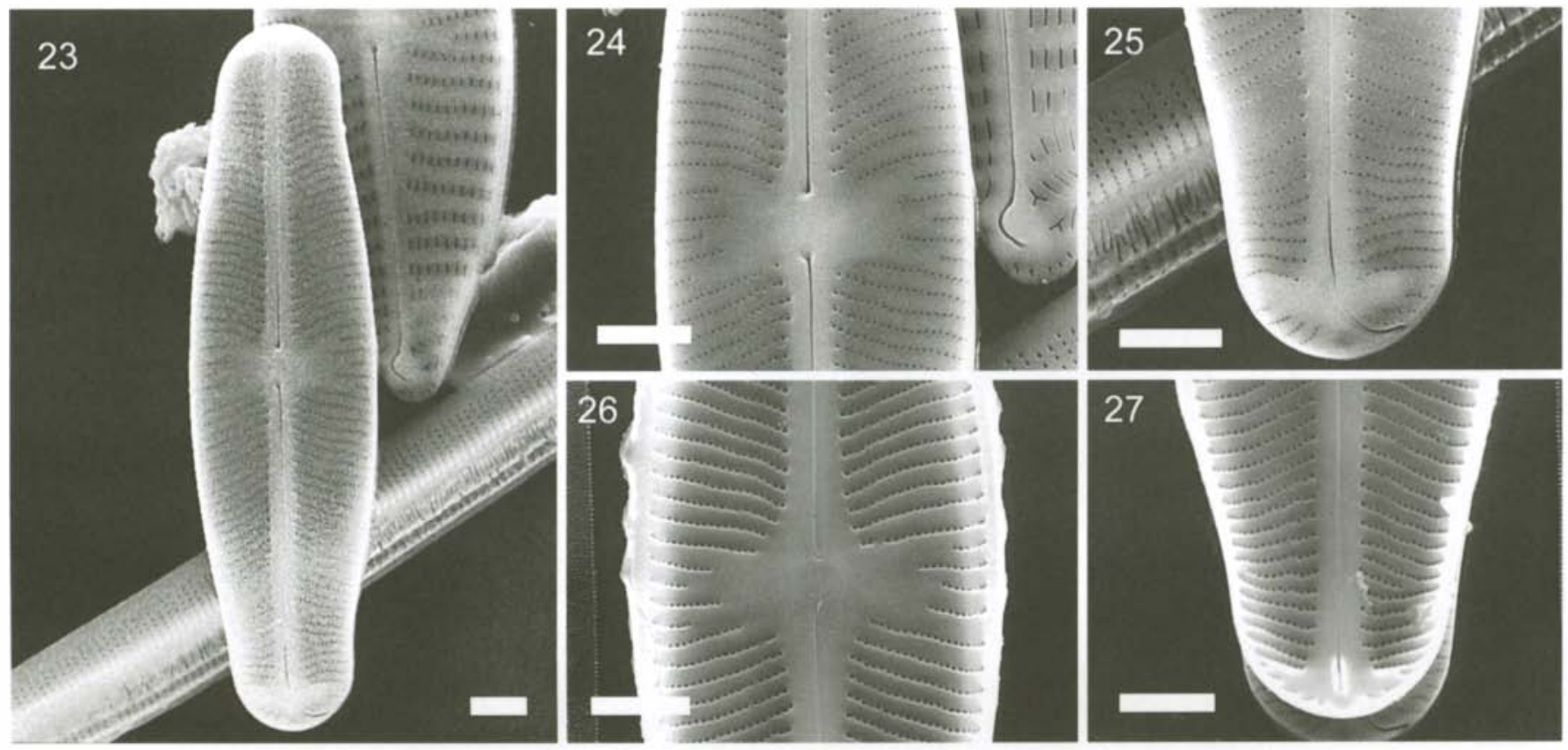

Figs 23-27. Sellaphora pupula (Blackford deme 'neat'), SEM. Epitype illustrations, from Blackford Pond material. Scale bars $=2 \mu \mathrm{m}$.

Fig. 23. Whole valve, exterior.

Fig. 24. Centre, exterior (primary side to the left).

Fig. 25. Pole, exterior, showing smoothly curved terminal fissure (primary side to the left).

Fig. 26. Centre, interior (primary side to the right).

Fig. 27. Pole, interior.

indicates complete prezygotic reproductive isolation between the four allogamous demes.

\section{Molecular genetic data}

Sequence data from small subunit ribosomal DNA (18S rDNA), ITSI-5.8S-ITS2 rDNA, and $r b c \mathrm{~L}$ have been obtained for 'small', 'rectangular' and 'capitate' [for 18S rDNA: Mann (1999, fig. 44) and Behnke et al. (2004); for ITS: Behnke (2001) and Behnke et al. (2004); and for $r b c$ L: D.G. Mann, G.E. Simpson \& C. Guihal, unpublished observations)]. All three gene sequences show significant divergence between the three demes. The phylogenetic relationships between the demes will be explored in further detail in future papers. The finding of greatest relevance to the current paper is that the ITS1 and ITS2 sequences of 'small' and either 'rectangular' or 'capitate' are so dissimilar as to make a phylogenetically useful alignment impossible, except over restricted regions (Behnke 2001). 'Rectangular' and 'capitate' are less dissimilar, but alignment is still highly uncertain and the lengths of the ITS sequences differ considerably [for 'rectangular', ITS 1 and ITS2 are 358 and $310-318$ bp, respectively (six cell clones studied); for 'capitate', they are 315 and 286 bp (one clone studied): Behnke et al. (2004)]. In algae and flowering plants, ITS sequences are usually alignable, and hence useful for studying phylogenetic relationships, in groups of closely related species or genera (e.g. Möller \& Cronk 1997; Denduangboripant \& Cronk 2000; Coleman 2001; LaJeunesse 2001). The extreme dissimilarity of the ITS sequences between three of the S. pupula demes, particularly between 'capitate' and 'rectangular', which are morphologically very similar, thus gives further strong support to the view that the demes are separate species. In addition, molecular data have revealed that a further deme, 'pseudocapitate', which is not found in Blackford Pond, is more closely related to 'rectangular' than is 'capitate'. Interbreeding between 'pseudocapitate' and Blackford 'rectangular' can occur in the laboratory (Behnke et al. 2004), but whether this occurs in nature is unclear because 'pseudocapitate' and 'rectangular' have not yet been found growing together and 'rectangular' seems to live in more highly eutrophic lakes than 'pseudocapitate'. Furthermore, although the ITS, $18 \mathrm{~S}$ rDNA and $r b c \mathrm{~L}$ sequences of these two demes are similar, they are not identical (Behnke et al. 2004; D.G. Mann, G.E. Simpson \& C. Guihal, unpublished observations).

\section{Geographical distribution}

The S. pupula complex is cosmopolitan. This conclusion (e.g. Hustedt 1927-1966, 1930; Krammer \& Lange-Bertalot 1986) is safe because $S$. pupula sensu lato is easily differentiated from other naviculoid diatoms by the combination of the presence of polar bars and of an approximately rectangular central area. The biogeography of the segregate species we describe below is unclear, however, because few old records of $S$. pupula can be reinterpreted in relation to our new classification: only papers and floras illustrated by good quality photographs contain enough information for reliable identification of demes in the $S$. pupula aggregate. None of the valves illustrated by Krammer \& Lange-Bertalot (1986) correspond to any of our new species, except their fig. 68:3, which is almost certainly of 'rectangular'; the geographical origin of this valve is not given. Hustedt $(1927-1966,1930)$ illustrated his floras with drawings, which, though good, do not permit identifica- 

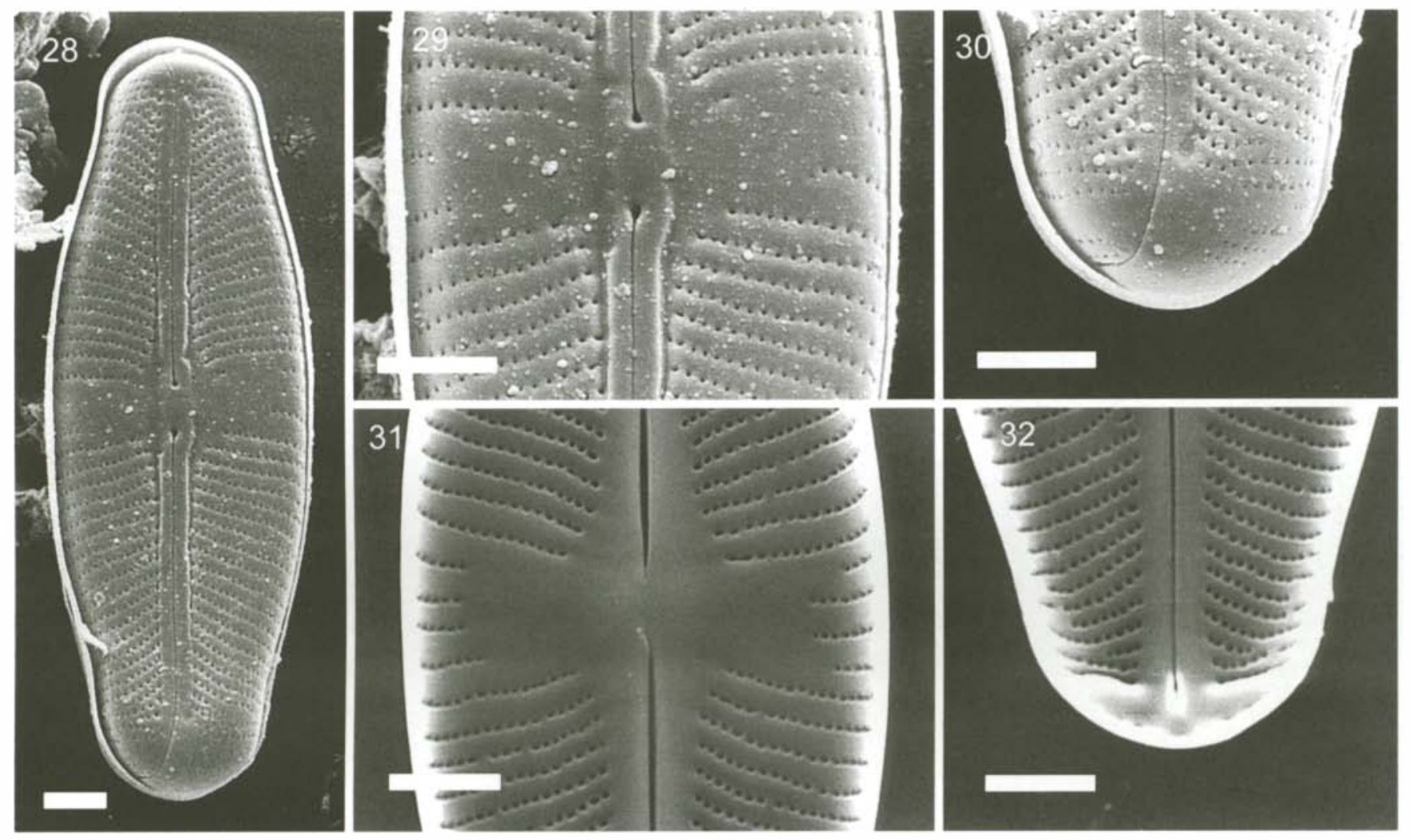

Figs 28-32. Sellaphora obesa (Blackford deme 'obese'), SEM. Scale bars $=2 \mu \mathrm{m}$.

Fig. 28. Whole valve, exterior.

Fig. 29. Centre, exterior (primary side to the right); note the raised raphe-sternum.

Fig. 30. Pole, exterior, showing smoothly curved terminal fissure (primary side to the right).

Fig. 31. Centre, interior.

Fig. 32. Pole, interior.

tion of the demes observed. Germain (1981, pl. 78, figs 4, 5) illustrated two valves that agree with 'obese' in dimensions, stria pattern and stria density. As with Krammer \& LangeBertalot's flora, however, the origin of the valves illustrated by Germain is not given.

The type of $S$. pupula is from northern Germany. Our own records of both $S$. pupula sensu stricto and the five 'Blackford' demes come from Scotland and England. All six demes may be widespread, but we do not have evidence for this, except that we have been able to cross 'capitate' clones from Blackford Pond with clones of similar appearance from the Crimea, Ukraine (data of V.A. Chepurnov \& D.G. Mann: see Mann 1999, p. 471). In the species descriptions below, we indicate only those records for which we have photographic evidence or voucher specimens.

\section{Species descriptions}

\section{Sellaphora pupula (Kiitzing) Mereschkowsky} $(1902$, p. 187)

Figs $4 \mathrm{a}-\mathrm{c}, 17,23-27$

SYNONYMS: Navicula pupula Kiitzing (1844, p. 93, pl. 30, fig. 40); S. pupula deme 'neat' sensu Mann (1984, 1989a, 1999).

LECTOTYPE: BM slide 17918, representing Kützing's material from Nordhausen, Germany: a specimen at England Finder reference M45/2 [designated by Mann (2001) and illustrated in his figs 2-6].
EPITYPES: Figs 4a-c, 17, 23-27 are here designated epitypes, to help clarify the nature of the lectotype on BM 17918. Fig. 17 is from Royal Botanic Garden Edinburgh (E): 'Blackford Pond, Dec. '83, mud (tissue), E16/4'. Edinburgh, Scotland, NT 253709. England Finder reference S43/4 [bottom and right-hand (RH) edges of the finder slide colocated with the top and left-hand ( $\mathrm{LH})$ edges of the specimen slide, when the label is to the left].

ETYMOLOGY: Kuitzing (1844) did not explain why he chose the epithet 'pupula', which is a feminine noun meaning 'a girl, little lass, puppet' or 'the pupil of the eye' (Lewis \& Short 1907). Thus, if the species were ever to be transferred to another genus, with a masculine or neuter name, the epithet pupula would remain unchanged, according to the International Code of Botanical Nomenclature, article 23.5 (Greuter et al. 2000).

DISTRIBUTION: Germany. Nordhausen (type locality). United Kingdom. Edinburgh lakes and ponds: Blackford Pond, Inverleith Pond, Dunsapie Loch, St Margaret's Loch and Figgate Loch (slides and voucher specimens E16, E319, 14.3.88, E317 and E321, respectively); Rae Loch, near Blairgowrie, Scotland (E330); Fenemere, Shropshire, England (E337).

The valves are narrowly elliptical with narrowly rostrate ends (Figs 4a-c, 17; cf. Barber \& Haworth 1981, figs 5.2, 7.10), 18.5-35 $\mu \mathrm{m}$ long (initial cells have not been observed, and so the maximum length is probably an underestimate) and 6.7-7.4 $\mu \mathrm{m}$ wide. The ratio of pole width to maximum width is c. $1: 1.5$ to $1: 1.9$. The axial area is narrow and straight (Figs $4 \mathrm{a}-\mathrm{c}, 17$ ). The central area is a rectangular or slightly bow-tie-shaped subfascia; its outline is somewhat irregular, as a result of the presence of approximately alternate long and 

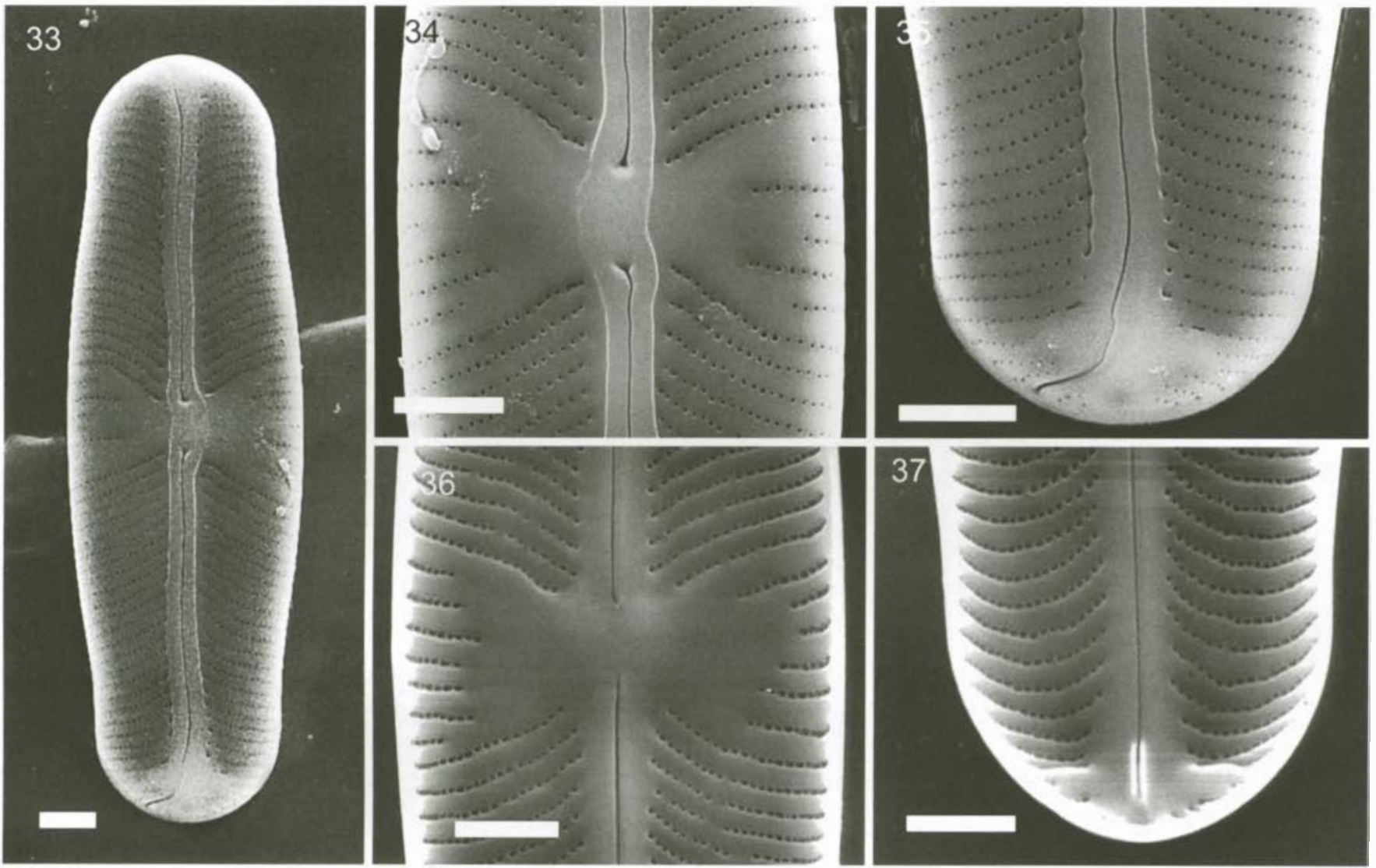

Figs 33-37. Sellaphora blackfordensis (Blackford deme 'rectangular'), SEM. Scale bars $=2 \mu$.m.

Fig. 33. Whole valve, exterior; note the sinuous raphe.

Fig. 34. Centre, exterior (primary side to the left); note the very prominent, raised raphe-sternum.

Fig. 35. Pole, exterior, showing curved terminal fissure (primary side to the right)

Fig. 36. Centre, interior (primary side to the right).

Fig. 37. Pole, interior.

short striae (Figs $4 \mathrm{a}-\mathrm{c}, 17$ ). The areolae are not resolved in LM (Fig. 17), but are \pm circular or elliptical and equally spaced poroids (Fig. 24), with a density of c. 65 in $10 \mu \mathrm{m}$ transapically. The striae are radiate centrally (though not as strongly as in any of the other species considered here, except S. obesa), becoming parallel or slightly convergent (especially in larger valves) near the poles (Figs $4 \mathrm{a}-\mathrm{c}, 17,23$ ); the striation density is $21.3-25.6$ in $10 \mu \mathrm{m}(\bar{x} 23.5)$. The striae and transapical ribs are of approximately equal height externally, so that the valve face appears plain (Figs 24, 25). The polar bars (Fig. 27) appear perpendicular to the apical axis in LM (Figs $4 \mathrm{a}-\mathrm{c}, 17$ ) or a little reflexed (in larger valves with convergent striae at the poles). Towards the centre of the valve, the raphe-sternum is slightly elevated externally, so that there are shallow grooves on either side of it and the striae are indented (Fig. 24). The raphe appears simple, straight and threadlike in LM (Figs 4a-c, 17; Barber \& Haworth 1981, fig. 12.1). The external central raphe endings are expanded and deflected towards the primary side (Fig. 24); the internal endings are also deflected towards the primary side (Fig. 26). The terminal fissures curve smoothly towards the secondary side (Fig. 25). The helictoglossa is narrow and elongate (Fig. 27).

Aspects of morphology and metric data are summarized in Table 4 to facilitate comparison and identification of the 'Blackford six'.
MATING SYSTEM AND AUXOSPORULATION: Auxosporulation has been observed only once ( $S$. pupula was the rarest of the Blackford demes throughout the period of most intense study during the 1980s) and was apparently autogamous: a single unpaired gametangium (18.5 $\mu \mathrm{m}$ long) gave rise to a single auxospore (Mann 1989a).

\section{Sellaphora obesa D.G. Mann \& M.M. Bayer, sp. nov.}

Figs 4d-f, 18, 28-32

SYNONYM: Sellaphora pupula deme 'obese' sensu Mann (1984, 1989a, 1999).

Valvae ellipticae vel anguste ellipticae polis late rostratis in medio quam in polis 1.8plo latiores, 20-40 $\mu \mathrm{m}$ longae, 8-10 $\mu \mathrm{m}$ latae. Area axialis angusta recta; raphosternum extus elevatum. Area centralis est subfascia irregularis (ita propter strias longas et breves alternantes) sed respectu ambitum limatum transverse oblonga vel dictu Angliae 'bow-tie' similis. Areolae poroides parvae circulares secus striam circa 53 in $10 \mu \mathrm{m}$ regulatim dispositae. Striae uniseriatae $18-21.5$ in $10 \mu \mathrm{m}$, ad centrum radiantes, ad polos aliquantum convergentes vel parallelae, striis geniculatis et brevibus intercalatis ad limitem inter series striarum polares et centrales saepe praesentibus. Transtra polaria ad axem apicalem perpendicularia vel paulo reflexa. Raphe simplex recta filiformis, extremis centralibus expansis versus latus primarium paulo flexis, fissuris terminalibus versus latus secundarium curvatis.

HOLOTYPE (DESIGNATED HERE): Royal Botanic Garden Edinburgh (E): 

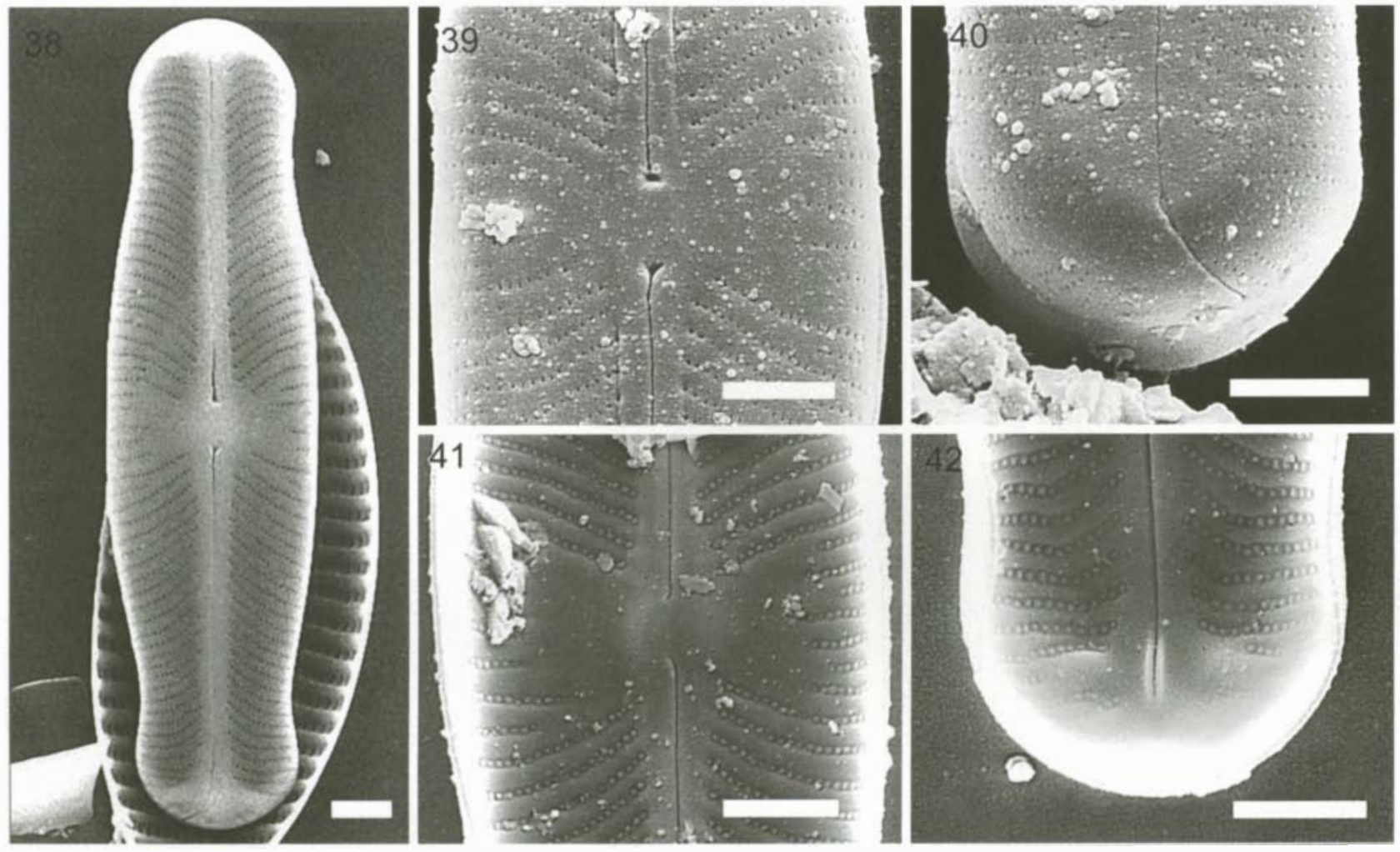

Figs 38-42. Sellaphora capitata (Blackford deme 'capitate'), SEM. Scale bars $=2 \mu \mathrm{m}$.

Fig. 38. Whole valve, exterior.

Fig. 39. Centre, exterior (primary side to the right); note the slightly raised raphe-sternum.

Fig. 40. Pole, exterior, showing terminal fissure abruptly bent above the helictoglossa (primary side to the left).

Fig. 41. Centre, interior (primary side to the left). Unlike the other valve interiors shown (Figs 26, 27, 31, 32, 36, 37, 46, 47, 51, 52), the valve in Figs 41, 42 still retains its hymenes, which appear as small domes occluding the poroids.

Fig. 42. Pole, interior.

'Blackford Pond, Dec. '83, mud (tissue), E16/4'. Edinburgh, Scotland, NT 253709. England Finder reference R49/0-R49/1 (bottom and $\mathrm{RH}$ edges of the finder slide colocated with the top and $\mathrm{LH}$ edges of the specimen slide, when the label is to the left).

ETYMOLOGY: The specific epithet is Latin for fat, stout or plump, and was chosen to maintain continuity with the informal naming system used by Mann (e.g. 1989a, 1999).

DISTRIBUTION: United Kingdom. Edinburgh lakes and ponds: Blackford Pond, Royal Botanic Garden Pond, Inverleith Pond, Dunsapie Loch, St Margaret's Loch and Figgate Loch (slides and voucher specimens E16, E2614, E319, 14.3.88, E317 and E321, respectively); Fenemere, Shropshire, England (E337).

The valves are elliptical or narrowly elliptical with rostrate ends (Figs 4d-f, 18; cf. Barber \& Haworth 1981, figs 5.2, 5.3, 7.10), 20-53 $\mu \mathrm{m}$ long and $8.1-10.0 \mu \mathrm{m}$ wide. The ratio of pole width to maximum width is $c .1: 1.8$. The axial area is narrow and straight (Figs $4 \mathrm{~d}-\mathrm{f}, 18$ ). The central area is a rectangular or slightly bow-tie-shaped subfascia; its outline is somewhat irregular, as a result of the presence of approximately alternate long and short striae (Figs 4d-f, 18). The areolae are not resolved in LM (Fig. 18) but are \pm circular or elliptical and equally spaced poroids (Figs 28-30), with a density of $c .53$ in $10 \mu \mathrm{m}$ transapically. The striae are radiate at the centre and convergent (or occasionally parallel in smaller valves) at the poles (Figs 4d-f, 18, 30); the striation density is $17.9-21.3$ in $10 \mu \mathrm{m}$. The frets separating the poroids are lower than the transapical ribs externally, so that the valve face is ridged, with grooves along the striae (Figs 29, 30). The polar silica bars (Fig. 32) appear perpendicular to the apical axis in LM or a little reflexed (Figs $4 \mathrm{~d}-\mathrm{f}, 18$ ). The raphesternum is elevated externally, with well-marked grooves separating it from the remainder of the valve face (Figs 29, 30). The raphe appears simple, straight and threadlike in LM (Figs 4d-f, 18; cf. Barber \& Haworth 1981, fig. 12.1). The external central raphe endings are slightly expanded and deflected a little towards the primary side (Fig. 29); the internal endings are also deflected towards the primary side (Fig. 31). The terminal fissures are hooked, curving smoothly towards the secondary side (Fig. 30). The helictoglossa is narrow and elongate (Fig. 30).

Sellaphora obesa resembles a larger, coarser (e.g. a lower striation density) and more robust version of $S$. pupula. Both have similar tapering valves, transversely elongate \pm rectangular central areas, straight raphes, and polar bars that are \pm perpendicular to the raphe (Table 4). The absence of ghost striae and the shape of the central area separate $S$. obesa and $S$. pupula from $S$. auldreekie and $S$. lanceolata, respectively, and valve shape separates them from $S$. blackfordensis and $S$. capitata.

MATING SYSTEM AND AUXOSPORULATION: Sellaphora obesa is allogamous (Mann 1999, fig. 62; D.G. Mann, unpublished observations), but the mating system is unknown. Gametangia of 22-36.5 $\mu \mathrm{m}(n \sim 20)$ have been observed to give rise to initial cells of $47-53 \mu \mathrm{m}(n=4)$. The length range is thus very similar to that of $S$. blackfordensis. 

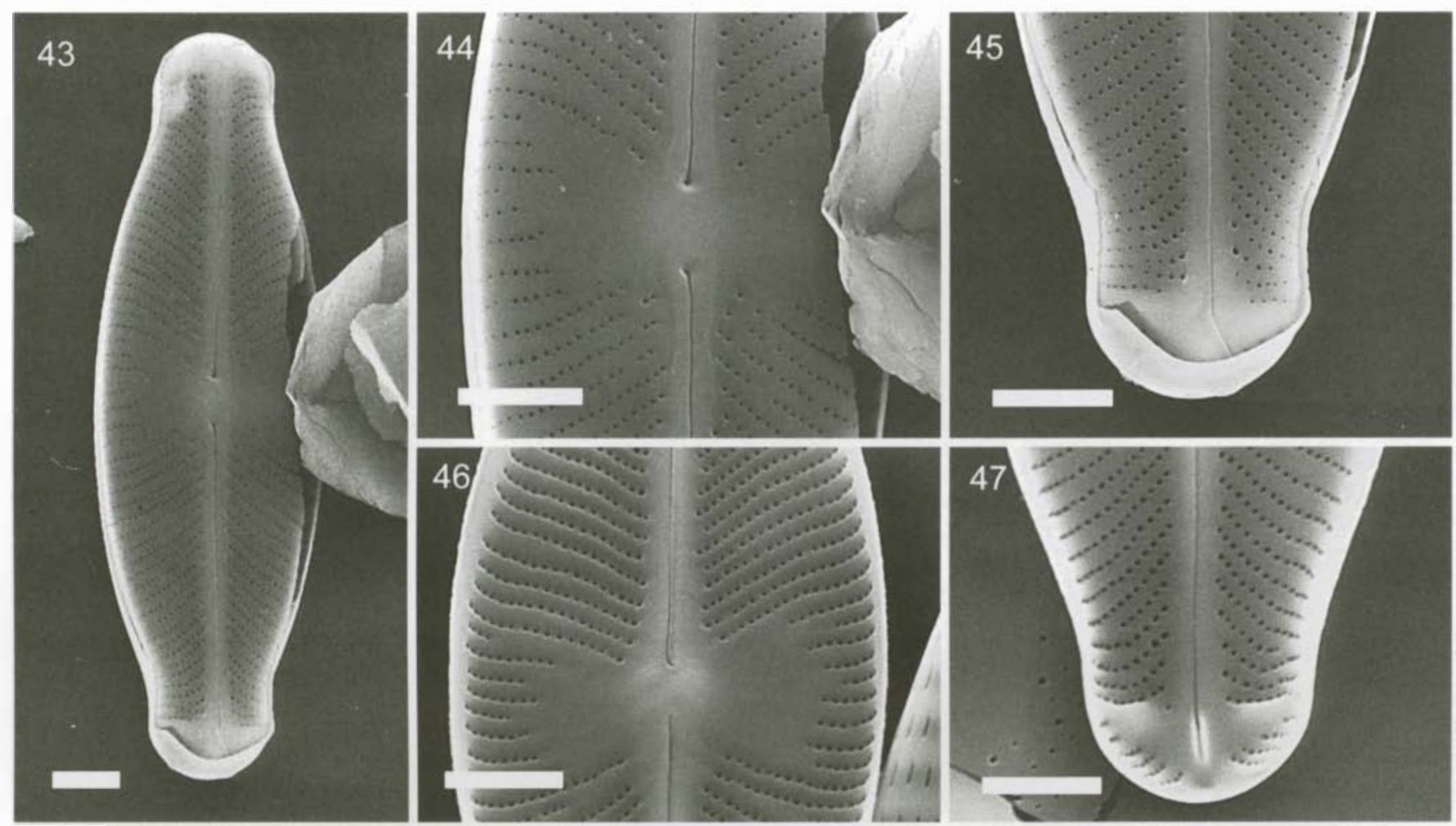

Figs 43-47. Sellaphora auldreekie (Blackford deme 'small'), SEM. Scale bars $=2 \mu \mathrm{m}$.

Fig. 43. Whole valve, exterior.

Fig. 44. Centre, exterior (primary side to the left).

Fig. 45. Pole, exterior, showing curved terminal fissure (primary side to the left); the apex is hidden by part of a girdle band.

Fig. 46. Centre, interior (primary side to the right).

Fig. 47. Pole, interior.
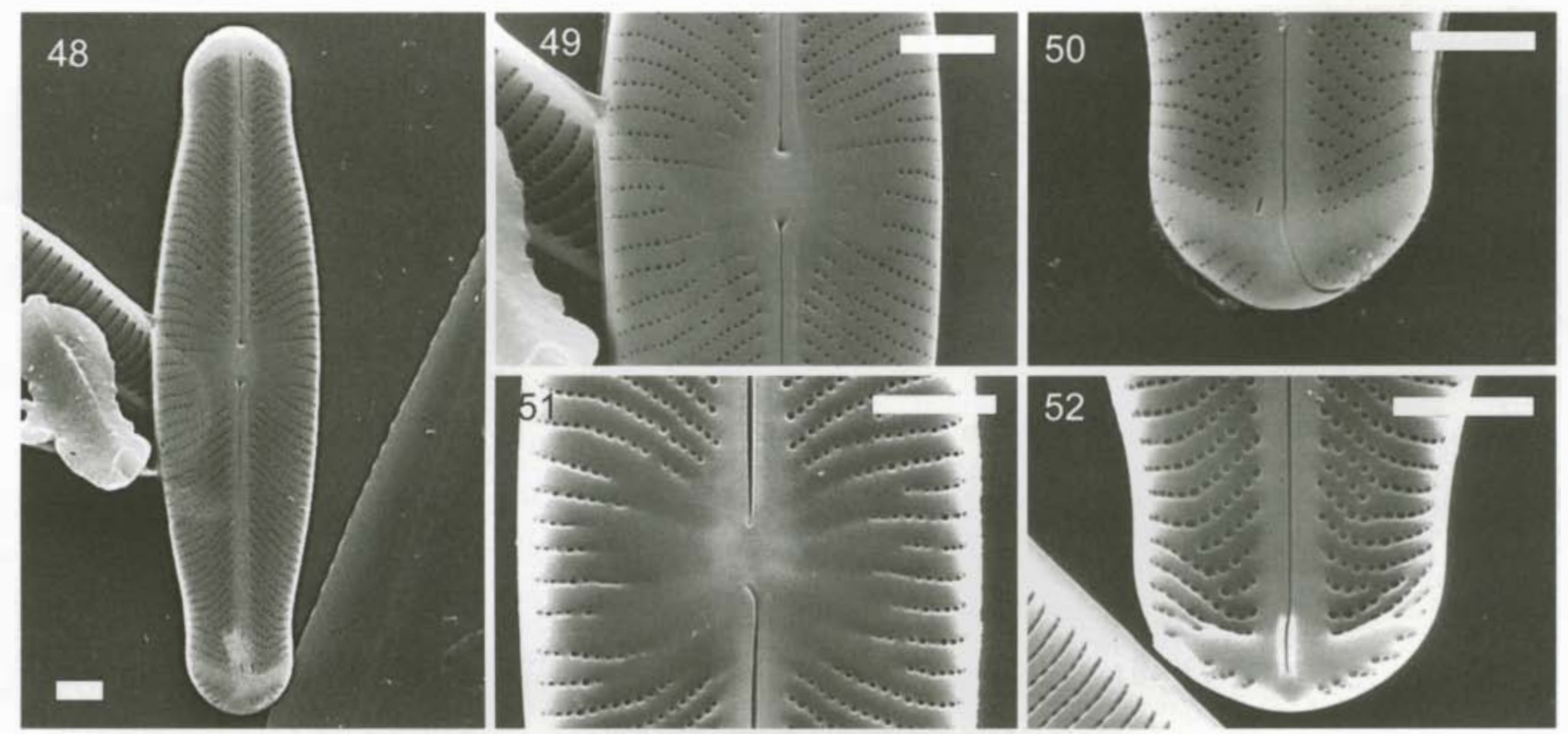

Figs 48-52. Sellaphora lanceolata (Blackford deme 'lanceolate'), SEM. Scale bars $=2 \mu \mathrm{m}$.

Fig. 48. Whole valve, exterior.

Fig. 49. Centre, exterior (primary side to the left); note the slight pitting and small grooves extending inwards from some striae (contributing to the 'ghost stria' appearance in LM: cf. Fig. 51).

Fig. 50. Pole, exterior, showing curved terminal fissure (primary side to the left)

Fig. 51. Centre, interior (primary side to the right); note the grooves that extend in from the ends of some striae (producing the 'ghost stria' effect in LM).

Fig. 52. Pole, interior. 
Table 3. Principal components analysis data for Legendre shape analysis, using the first nine even Legendre polynomials $\left(P_{0}, P_{2}, P_{4}, P_{6}, P_{8}\right.$, $P_{10}, P_{12}, P_{14}$ and $P_{16}$ ) (see Fig. 15). Eigenanalysis of the correlation matrix. The first four principal components together account for $91 \%$ of the total variance.

\begin{tabular}{|c|c|c|c|c|c|c|c|c|}
\hline & $\mathrm{PCl}$ & $\mathrm{PC} 2$ & PC3 & $\mathrm{PC} 4$ & PC5 & PC6 & PC7 & PC8 \\
\hline Proportion of variance $(\%)$ & 42.1 & 25.4 & 14.7 & 9.0 & 4.5 & 2.1 & 1.3 & 0.7 \\
\hline Cumulative proportion of variance $(\%)$ & 42.1 & 67.5 & 82.2 & 91.2 & 95.7 & 97.8 & 99.2 & 99.9 \\
\hline \multicolumn{9}{|l|}{ Variable } \\
\hline$P_{0}$ & 0.05 & -0.56 & -0.29 & -0.41 & 0.15 & 0.09 & -0.10 & 0.15 \\
\hline$P_{2}$ & -0.40 & 0.29 & 0.20 & 0.35 & -0.32 & 0.25 & -0.14 & 0.07 \\
\hline$P_{4}^{2}$ & 0.36 & 0.38 & -0.27 & 0.14 & 0.00 & -0.56 & 0.18 & 0.47 \\
\hline$P_{\mathrm{I} 0}^{\circ}$ & -0.46 & 0.12 & 0.04 & -0.31 & 0.11 & -0.27 & 0.69 & -0.31 \\
\hline$P_{12}$ & -0.09 & 0.55 & 0.05 & -0.37 & 0.61 & 0.08 & -0.42 & -0.01 \\
\hline$P_{14}$ & 0.44 & 0.14 & 0.30 & -0.11 & 0.11 & 0.61 & 0.50 & 0.23 \\
\hline$P_{16}$ & 0.24 & 0.02 & 0.61 & -0.49 & -0.43 & -0.31 & -0.20 & -0.05 \\
\hline
\end{tabular}

\section{Sellaphora blackfordensis D.G. Mann \& S. Droop, sp. nov.}

Figs $4 \mathrm{~g}-\mathrm{i}, 19,33-37$

SYNONYM: Sellaphora pupula deme 'rectangular' sensu Mann (1984, 1989a, 1999).

Valvae lineari-ellipticae (fere lineares) polis latis subcapitatis, 19$57 \mu \mathrm{m}$ longae (solum in culturam interdum $9 \mu \mathrm{m}$ ), 8.1-9.3 $\mu \mathrm{m}$ latae. Area axialis angusta recta; raphosternum extus manifeste elevatum. Area centralis est subf ascia irregularis (ita propter strias longas et breves alternantes) sed respectu ambitum limatum dictu Angliae 'bow-tie' similis. Areolae poroides parvae circulares secus striam c. 55 in $10 \mu \mathrm{m}$ regulatim dispositae. Striae uniseriatae $18-$ 22 in $10 \mu \mathrm{m}$ pro parte maxima radiantes, prope polos interdum parallelae. Transtra polaria ad polos propinquissima, per microscopium lucis visa radiantia vel parallela atque striae. Raphe simplex sinuolata filiformis, extremis centralibus expansis versus latus primarium valde flexis, fissuris terminalibus versus latus secundarium curvatis.

HOLOTYPE (DESIGNATED HERE): Royal Botanic Garden Edinburgh (E): 'Blackford Pond, Dec. '83, mud (tissue), El 6/4'. Edinburgh, Scotland, NT 253709. England Finder reference S39/4 (bottom and RH edges of the finder slide colocated with the top and LH edges of the specimen slide, when the label is to the left).

ETYMOLOGY: This species is named after the pond in Edinburgh where one of us (D.G.M.) began studies of the $S$. pupula complex in the early 1980s and discovered reproductive isolation between what we are now calling S. blackfordensis, S. capitata and S. auldreekie (Mann 1984).

DISTRIBUTION: United Kingdom. Edinburgh lakes and ponds: Blackford Pond, Royal Botanic Garden Pond, Dunsapie Loch and Figgate Loch (slides and voucher specimens E16, E2614, 14.3.88 and E321, respectively); Rae Loch, near Blairgowrie, Scotland (E330); Fenemere, Shropshire, England (E337).

The valves are narrowly elliptical with subcapitate ends (Figs 4g-i, 19; cf. Barber \& Haworth 1981, figs 5.3, 7.13), 19-57 $\mu \mathrm{m}$ long and $8.1-9.3 \mu \mathrm{m}$ wide. The axial area is narrow and straight (Figs $4 \mathrm{~g}-\mathrm{i}, 19$ ). The central area is a bowtie-shaped subfascia; its outline is somewhat irregular, as a result of the presence of approximately alternate long and short striae (Figs $4 \mathrm{~g}-\mathrm{i}, 19$ ). The areolae cannot be resolved in LM (Fig. 19), but are \pm circular or elliptical and equally spaced poroids (Figs 34, 35), with a density of c. 55 in 10 $\mu \mathrm{m}$ transapically. The striae are radiate throughout, becoming almost parallel near the poles (Figs 4g-i, 19, 33, 35); their density is $18.3-22.1$ in $10 \mu \mathrm{m}$. In LM, the polar bars (Fig.
37) appear angled out towards the poles (Fig. $4 g-i$ ). The raphe-sternum is elevated and prominent externally for almost the whole of its length (Figs 33-35). The raphe appears simple in LM and is threadlike and clearly undulate (Figs $4 \mathrm{~g}-\mathrm{i}, 19$, 33; cf. Barber \& Haworth 1981, fig. 12.2). The external central raphe endings are expanded and strongly deflected towards the primary side (Fig. 34); the internal endings are also deflected towards the primary side (Fig. 36). The terminal fissures are bent towards the secondary side (Fig. 35); their curvature is complex, with inflections either side of where the polar bars lie internally (this subtlety was consistent between valves collected in Blackford Pond, Fenemere, and Figgate Loch). The helictoglossa is narrow and elongate (Fig. 37).

Sellaphora blackfordensis and S. capitata (see below) both have valves that can loosely be called 'linear-lanceolate'. The differences between them in shape are subtle (Fig. 4), although contour segment analysis (Fig. 16) shows that they are real. Describing the differences exactly in words is not possible, however, and in our judgement it is unsafe to attempt identification by eye on the basis of shape alone. Sellaphora blackfordensis and $S$. capitata can be separated from each other quite easily, however, by a combination of the tendency of $S$. capitata to be more capitate, the greater width of $S$. blackfordensis at any given length (Fig. 13; see also Mann 1989a; Mann et al. 1999), and the heavier silicification and more obviously sinuous raphe of S. blackfordensis. In addition, the polar bars tend to be slightly radial in $S$. blackfordensis, but parallel to the transapical axis in $S$. capitata (Table 4 ). It will be obvious from this attempt at differential diagnosis that it is easiest to identify the two species when both are present alongside each other in the same material, as can happen. If they are not co-occurring, or if there are other similar demes present (e.g. Behnke et al. 2004), identification can be extremely difficult.

MATING SYSTEM AND AUXOSPORULATION: Auxosporulation is allogamous (Mann 1984, 1988a, 1989, 1999; Mann et al. 1999). In nature, gametangia $19-36 \mu \mathrm{m}$ long $(n \gg 500)$ give rise to initial cells of $40.5-57 \mu \mathrm{m}(n>200)$ and we have not observed any vegetative cell smaller than $19 \mu \mathrm{m}$. In culture, however, much smaller vegetative cells (down to $9 \mu \mathrm{m}$ ) can be formed and the smallest of them are apparently unable to complete sexual reproduction (Mann et al. 1999); we have not 
included cells smaller than those found in nature in our taxon description.

Sellaphora blackfordensis has a complex mating system. Some clones are unisexual (male or female), with little or no capacity for intraclonal sexual reproduction; examples of these include the two clones Rect-13 (male) and Rect-13B (female) studied by Mann et al. (1999). Other clones exhibit moderate levels of intraclonal reproduction (selfing) and the behaviour of their gametes in interclonal crosses varies according to the clone with which they are mated (V.A. Chepurnov \& D.G. Mann, unpublished observations). Sellaphora blackfordensis is thus a 'monoecious-dioecious' species (sensu Roshchin 1994; Roshchin \& Chepurnov 1999).

\section{Sellaphora capitata D.G. Mann \& S.M. McDonald, sp. nov.}

Figs $4 \mathbf{j}-1,20,38-42$

SYNONYM: Sellaphora pupula deme 'capitate' sensu Mann (1984, 1989a, 1999).

Valvae lineari-ellipticae, polis subcapitatis in valvis maioribus capitatis, 19-44 $\mu \mathrm{m}$ longae, 7.2-8.2 $\mu \mathrm{m}$ latae. Area axialis angusta recta; raphosternum extus paulo elevatum praecipue ad centrum. Area centralis est subfascia irregularis (ita propter strias longas et breves alternantes) sed respectu ambitum limatum dictu Angliae 'bow-tie' similis. Areolae poroides parvae circulares secus striam c. 62 in $10 \mu \mathrm{m}$ regulatim dispositae. Striae uniseriatae 16-22 in 10 $\mu \mathrm{m}$, pro parte maxima radiantes, prope polos parallelae. Transtra polaria ad axem apicalem perpendicularia. Raphe simplex paulo sinuolata filiformis, extremis centralibus expansis versus latus primarium flexis, fissuris terminalibus super helictoglossam versus latus secundarium abrupte flexis.

holotype (DEsignated HeRE): Royal Botanic Garden Edinburgh (E). 'Blackford Pond, Dec. '83, mud (tissue), El6/4'. Edinburgh, Scotland, NT 253709. England Finder reference R41/0 (bottom and RH edges of the finder slide colocated with the top and LH edges of the specimen slide, when the label is to the left).

ETYMOLOGY: The specific epithet is Latin for capitate, i.e. provided with a knob-like tip, and was chosen to maintain continuity with the informal naming system used by Mann (1989a, 1999).

DISTRIBUTION: United Kingdom. Edinburgh lakes and ponds: Blackford Pond, Dunsapie Loch and Figgate Loch (slides and voucher specimens E16, 14.3.88 and E321, respectively); Fenemere, Shropshire, England (E337). Probably also the Crimea, Ukraine (V.A. Chepurnov \& D.G. Mann, unpublished observations).

The valves are narrowly elliptical with subcapitate poles (these are more strongly capitate in larger valves) (Figs $4 \mathrm{j}-1$, 20; cf. Barber \& Haworth 1981, figs 5.3, 7.13), 19-44 $\mu \mathrm{m}$ long and 7.2-8.2 $\mu \mathrm{m}$ wide. The axial area is narrow and straight, and the raphe appears as a straight line in LM (Figs $4 \mathrm{j}-\mathrm{l}, 20$ ) or very slightly undulate (cf. Fig. 38). The central area is a bow-tie-shaped subfascia; its outline is somewhat irregular, as a result of the presence of approximately alternate long and short striae (Figs 4j-1, 19). The areolae cannot be resolved in LM (Fig. 20), but are \pm circular or elliptical and equally spaced poroids (Fig. 39), with a density of c. 62 in $10 \mu \mathrm{m}$ transapically. Figures 41,42 show a valve that has not been significantly eroded or dissolved during specimen preparation and storage. As a result, the small domed hymenes (sieve membranes: Mann 1981) are still visible at the inner apertures of the poroids (cf. Mann 1989b, figs 6, 7). The striae are mostly radiate, becoming parallel near the poles (Figs $4 \mathrm{j}-$ $1,20,38)$, with a density of $16.2-22.3$ in $10 \mu \mathrm{m}$; many striae terminate in one or a few larger poroids at the axial area (Fig. 39). The polar bars are relatively more distant from the apex than in $S$. blackfordensis and are perpendicular to the raphe (Figs $4 \mathrm{j}-1,20,42$ ). The raphe-sternum is flush with the valve face near the poles, but slightly elevated near the centre (Figs 38-40). The raphe appears simple in LM and is slightly undulate and threadlike (Figs 4j-1, 20, 38; cf. Barber \& Haworth 1981, figs 12.1, 12.2). The external central raphe endings are expanded and deflected towards the primary side (Fig. 39); the internal endings are also deflected towards the primary side (Fig. 41). Above the helictoglossa, which is narrow and elongate (Fig. 42), the terminal fissure is abruptly bent towards the secondary side (Fig. 40).

For LM differences between $S$. capitata and $S$. blackfordensis, which is most similar to $S$. capitata of the six species treated here, see under $S$. blackfordensis and Table 4.

MATING SYSTEM AND AUXOSPORULATION: Auxosporulation is allogamous (Mann 1984, 1988a, 1989b, 1999; Mann et al. 1999). In nature, gametangia $19-30.5 \mu \mathrm{m}$ long $(n \gg 500)$ give rise to initial cells of 34-43 $\mu \mathrm{m}(n>200)$ and we have not observed any vegetative cell smaller than $19 \mu \mathrm{m}$, as in $S$. blackfordensis. In culture, we have observed initial cells up to $44 \mu \mathrm{m}$ long, and much smaller vegetative cells (down to $10 \mu \mathrm{m}$ ) can be formed, the smallest cells being apparently unable to complete sexual reproduction (Mann et al. 1999). Our taxon description, however, refers only to the range of form in natural populations.

Sellaphora capitata clones show almost no capacity for intraclonal auxosporulation (Mann et al. 1999; D.G. Mann \& V.A. Chepurnov, unpublished observations). This diatom is dioecious and clones produce either 'male' or 'female' gametangia, but not both.

\section{Sellaphora auldreekie D.G. Mann \& S.M. McDonald, sp. nov.}

Figs $4 \mathrm{~m}-\mathrm{O}, 21,43-47$

SYNONYM: Sellaphora pupula deme 'small' sensu Mann (1984, 1989a, 1999).

Valvae ellipticae polis valde rostratis angustis, in medio quam in polis 2-3plo latiores, $15-35 \mu \mathrm{m}$ longae, $6.6-8 \mu \mathrm{m}$ latae. Area axialis angusta recta; raphosternum extus non vixve elevatum, fronte igitur plana. Area centralis est subfascia angulis acutis dictu Angliae 'bow-tie' similis. Areolae poroides parvae circulares secus striam c. 65 in $10 \mu \mathrm{m}$ regulatim dispositae. Striae uniseriatae 19-24 in 10 $\mu \mathrm{m}$ pro parte maxima radiantes, in valvis maioribus prope polos convergentibus. Transtra polaria ad axem apicalem perpendicularia. Raphe simplex recta filiformis, extremis centralibus expansis versus latus primarium paulo flexis, fissuris terminalibus versus latus secundarium flexis.

HOLOTYPE (DESIGNATED HERE): Royal Botanic Garden Edinburgh (E): 'Blackford Pond, Dec. '83, mud (tissue), E16/4'. Edinburgh, Scotland, NT 253709. England Finder reference R38/0 (bottom and RH edges of the finder slide colocated with the top and LH edges of the specimen slide, when the label is to the left).

ETYMOLOGY: This deme has previously been referred to as 'small', for which the Latin is parvus. We considered using this as the epithet but considered that there was no advantage in doing so because few biologists now have sufficient Latin to know what parvus means, so that parvus would not provide an obvious link between any new data and the papers by Mann (1989a, 1999). We have therefore chosen to honour the city where 'small' has been studied for the last 20 years. The colloquial Old Scots name for Edinburgh is 'auld reekie', which refers to the smoke and blackened state of 
Table 4. Summary of the LM characteristics of six species of Sellaphora described in this paper.

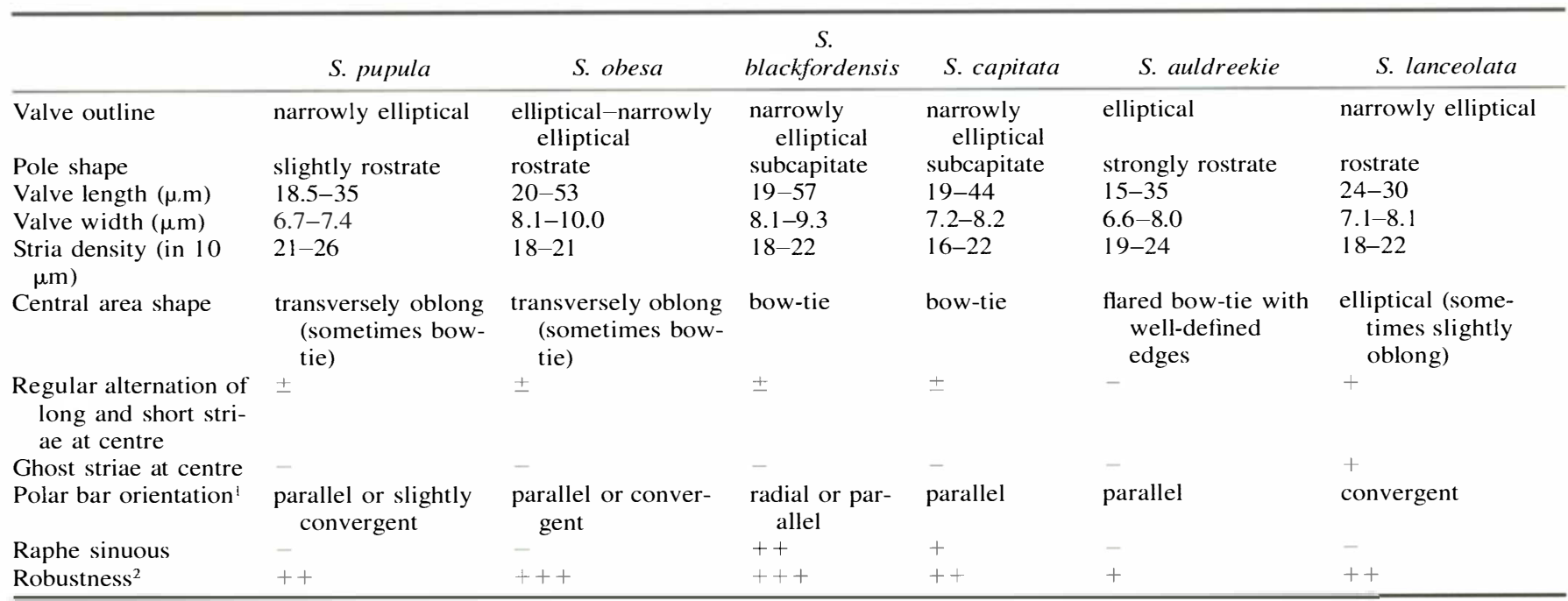

\footnotetext{
Orientation relative to the transapical axis (raphe), as for striae: convergent, angled back towards the valve centre; parallel, perpendicular to the raphe; radial, angled towards the pole.

${ }^{2}$ Subjective assessment of relative silicification (among the six species only).
}

the 19th and early 20th century city (Grant \& Murison 1968), before measures were introduced to curb air pollution. The pronunciation is /'bsld 'rikki/ or /'asld 'riski/.

DISTRIBUTION: United Kingdom. Edinburgh lakes and ponds: Blackford Pond, Dunsapie Loch and Figgate Loch (slides and voucher specimens E16, 14.3.88 and E321, respectively); Fenemere, Shropshire, England (E337).

The valves are elliptical with strongly rostrate ends (Figs 4m-o, 21; cf. Barber \& Haworth 1981, figs 5.2, 7.10), 15-35 $\mu . \mathrm{m}$ long and $6.6-8.0 \mu \mathrm{m}$ wide. The ratio of pole width to maximum width is $c$. $1: 2.3$. The axial area is narrow and straight (Figs $4 \mathrm{~m}-\mathrm{O}, 21$ ). The central area is an acute-angled subfascia, like a flaring bow-tie (Figs $4 \mathrm{~m}-\mathrm{o}, 21$ ) (Barber \& Haworth 1981, fig. 11.18). The areolae are not resolved in LM (Fig. 21), but are \pm circular or elliptical and equally spaced poroids (Figs 44-47), with a density of c. 65 in 10 $\mu \mathrm{m}$ transapically. The striae are radiate, becoming parallel or, in larger valves, convergent at the poles (Figs $4 \mathrm{~m}-\mathrm{o}, 21$ ); their density is $19.2-23.7$ in $10 \mu \mathrm{m}$. The polar bars (Fig. 47) are perpendicular to apical axis or very slightly reflexed (in large valves) (Figs $4 \mathrm{~m}-\mathrm{O}, 21$ ). The raphe-sternum is not or scarcely elevated externally (Figs 43-45). The raphe appears simple, straight and threadlike in LM (Figs 4m-o, 21; cf. Barber \& Haworth 1981, fig. 12.1). The external central raphe endings are expanded and deflected towards the primary side (Fig. 44); the internal endings are also deflected towards the primary side (Fig. 46). The terminal fissures are bent towards the secondary side (Fig. 45; unfortunately, part of the fissure is obscured by girdle elements). The helictoglossa is narrow and elongate (Fig. 47).

Sellaphora auldreekie is the smallest of the six species described here and can be separated from the other nonlinear species (pupula, obesa and lanceolata) by a combination of size, narrowly rostrate apices, lack of ghost striae, and discrete bow-tie-shaped central area (Table 4). Sellaphora auldreekie is very similar to $S$. rostrata (Hustedt) Johansen (Johansen et al. 2004), which was previously regarded as a variety or form within 'Navicula' pupula (Hustedt 1911, 1927-1966) or given no taxonomic status (Krammer \& Lange-Bertalot 1986). Both species are small-celled (valve width $c .7 \mu \mathrm{m}$ ) and have valves with an elliptical body and strongly rostrate apices. However, the three specimens from the lectotype population of $S$. rostrata illustrated by Simonsen (1987, pl. 5, figs 5-7: one of these is also shown at http://diatomwebserver..awi-bremerhaven.de/ Curator/) differ from $S$. auldreekie in having less strongly radiate striae at the centre and consequently a less strongly flared central area. The central area of $S$. auldreekie is almost always acutely angled, so that it resembles a butterfly, whereas in $S$. rostrata the central area is more rectangular (this is evident also in Hustedt's 1911 drawing) and it is also more irregular, at least in the three specimens shown by Simonsen (contrast Simonsen's figures with the Blackford $S$. auldreekie at http://rbgweb2.rbge.org.uk/algae/research/mann_etal_2004/pictures.htm). It is highly unlikely that $S$. rostrata (as var. or f. rostrata) was identified consistently during the 20th century, even by Hustedt. Illustrations in Hustedt (1927-1966, fig. 1255) seem to show a third species, separated from both $S$. rostrata and $S$. auldreekie by its rounded central area and subcapitate apices; this may be the same as the specimen identified as 'Navicula pupula var. rostrata Hustedt' by Krammer \& Lange-Bertalot (1986, fig. 68/ 12), which was found in another of Hustedt's slides (N13/92), from Pitkajärvi, Finland. The single drawing in Hustedt (1930, fig. 467e), used between 1930 and 1960 as the standard text for identifying most species of Navicula Bory sensu lato, resembles none of the above.

MATING SYSTEM AND AUXOSPORULATION: Sellaphora auldreekie is allogamous (Mann 1984, 1989b, 1999). In nature, gametangia of $15-24.5 \mu \mathrm{m}(n>100)$ have been observed to give rise to initial cells of $30-35 \mu \mathrm{m}(n \sim 40)$. As in $S$. blackfordensis and $S$. capitata, much smaller cells are produced in culture than have been observed in nature, down to $10 \mu \mathrm{m}$ or less. Smaller initial cells have also been produced in culture. For example in crosses between two clones with 
gametangia of $c .11-14 \mu \mathrm{m}$, initial cells of 20.5-31.5 $\mu \mathrm{m}$ were produced.

The mating system of $S$. auldreekie has not been studied as intensively as those of $S$. blackfordensis and $S$. capitata, but data for 16 clones, involving 85 crosses out of a possible total of 120 , indicate that $S$. auldreekie is basically dioecious, though with more capacity for intraclonal reproduction than in S. capitata (V.A. Chepurnov \& D.G. Mann, unpublished observations).

\section{Sellaphora lanceolata D.G. Mann \& S. Droop, sp. nov.}

$$
\text { Figs } 4 p-r, 22,48-52
$$

SYNONYM: Sellaphora pupula deme 'lanceolate' sensu Mann (1984, 1989a, 1999).

Valvae anguste ellipticae polis rostratis, in medio quam in polis 1.7plo latiores, $24-31 \mu \mathrm{m}$ longae, $7.1-8.1 \mu \mathrm{m}$ latae. Area axialis angusta recta; raphosternum extus paulo elevatum praecipue ad centrum. Area centralis irregularis (ita propter strias longas et breves alternantes) sed respectu ambitum limatum elliptica vel transverse oblonga. Circum aream centralem striae longae et breves inter se alternant, quae introrsum in fossas non profundas quasi idola prolongatae sunt. Areolae poroides parvae circulares secus striam circa 55 in $10 \mu \mathrm{m}$, regulatim dispositae. Striae uniseriatae 18-21.5 in 10 $\mu \mathrm{m}$, ad centrum radiantes, ad polos valde convergentes, limite inter series striarum duas has striis geniculatis vel brevibus intercalatis signati. Transtra polaria valde reflexa, respectu raphem sub angulo acuto igitur patentia. Raphe simplex recta filiformis, extremis centralibus expansis versus latus primarium vix flexis, fissuris terminalibus versus latus secundarium curvatis.

HOLOTYPE (DESIGNATED HERE): Royal Botanic Garden Edinburgh (E): 'Blackford Pond, Dec. '83, mud (tissue), E16/4'. Edinburgh, Scotland, NT 253709. England Finder reference S41/0 (bottom and RH edges of the finder slide colocated with the top and LH edges of the specimen slide, when the label is to the left).

ETYMOLOGY: The specific epithet is Latin for lanceolate, i.e. with a narrow shape broadest at the centre and tapering to either end, as in a spear tip; it was chosen to maintain continuity with the informal naming system used by Mann (1989a, 1999).

DISTRIBUTION: United Kingdom. Edinburgh lakes and ponds: B lackford Pond, Dunsapie Loch and Figgate Loch (slides and voucher specimens E16, 14.3.88 and E321, respectively).

The valves are narrowly elliptical with rostrate ends (Figs 4p-r, 22; cf. Barber \& Haworth 1981, figs 5.3, 7.10), 24-30 $\mu \mathrm{m}$ long and $7.1-8.1 \mu \mathrm{m}$ wide. The ratio of pole width to maximum width is $c .1: 1.7$. The axial area is narrow and straight (Figs 1, 4p-r, 22). The central area is irregular in outline, because of the presence around it of approximately alternate long and short striae, but overall it is elliptical or transversely oblong (Figs $1,4 p-r, 22$ ). The central area is invaded by 'ghost striae' (Figs 1, 22), which are inward extensions of the normal striae that lack poroids: they are thinner strips of silica, appearing as grooves internally (Fig. 51) and sometimes also externally (Fig. 49), especially if the valves have begun to dissolve. They probably represent areas that have been infilled during development of the valve (cf. Cox 2001), but this cannot be confirmed without studies of valve ontogeny. The areolae are not resolved in LM, but are \pm circular or elliptical and equally spaced poroids (Figs 49, 50), with a density of $c .55$ in $10 \mu \mathrm{m}$ transapically. The striae are radiate over most of the valve but convergent at poles, with an abrupt change between the two series, usually marked by geniculate striae and short striae that originate by the raphe but are truncated \pm midway to the margin (Figs 1, 4p-r, 22,
$50,52)$; the striation density is $17.7-21.8$ in $10 \mu \mathrm{m}$. The striae and transapical ribs are of approximately equal height externally, so that the valve face appears plain (Figs 49, 50). The polar bars (Fig. 52) appear sharply angled towards the central area in LM (Figs 1, 4p-r, 22: see also Fig. 50, where electron beam penetration reveals the positions of the bars). The raphe appears simple, straight and threadlike in LM (Figs 1, 4p-r, 22; Barber \& Haworth 1981, fig. 12.1). The external central raphe endings are expanded and scarcely deflected towards the primary side (Fig. 49). The terminal fissures curve smoothly towards the secondary side (Fig. 50). The helictoglossa is narrow and elongate (Fig. 52).

Among the Sellaphora species treated here, S. lanceolata is easily distinguished by a combination of its lanceolate shape, 'ghost striae' and reflexed polar bars (Table 4).

MATING SYSTEM AND AUXOSPORULATION: Auxosporulation has never been observed during over a decade of observations of $S$. lanceolata both in Blackford Pond and in several other British lakes. The size range within a population is always small, relative to what is found in most other species of the $S$. pupula complex, and the size spectrum does not appear to change systematically through time [contrast, for example, various species studied by Wesenberg-Lund (1908), Nipkow (1927) and others: see Mann (1988b)]. Consequently, we think it very likely that $S$. lanceolata avoids size reduction in nature, does not perform meiosis or auxosporulation, and is wholly asexual. However, this conclusion is based on negative evidence and we have been unable thus far to culture $S$. lanceolata.

\section{General discussion}

We have previously concluded (e.g. Mann \& Droop 1996; Mann 1999) that the species concept in diatoms has of ten been too wide and that there are many more species than are currently recognized, even in areas of the world that are comparatively well known, such as northern Europe. The data presented here are consistent with this view. The LM differences between $S$. capitata and S. blackfordensis - amounting to a $c$. $1 \mu \mathrm{m}$ difference in width at any given length, a slightly more sinuous raphe in $S$. blackfordensis and a difference in shape that is so small that the human eye and a well-tried shape measure (Legendre polynomials) fail to provide clear separation between them - are so subtle that it is not surprising that previous generations of diatomists have underestimated the diversity of the group. The discovery of the 'pseudocapitate' deme studied by Behnke et al. (2004) makes this point even more strongly. Valves of this deme are morphologically intermediate between $S$. capitata and S. blackfordensis and during early phases of the study by Behnke et al. (2004), two of the present authors (D.G.M. and V.A.C.) incorrectly and inconsistently identified different 'pseudocapitate' clones, despite our long experience of the $S$. pupula complex, some clones being allocated to the 'rectangular' deme (S. blackfordensis), others being thought related to $S$. capitata.

We undertook the morphometric analyses reported here primarily to investigate how useful different shape measures and other metrics might be in future, in analyses of other samples containing the $S$. pupula complex, rather than to determine how many Sellaphora species there are in Blackford Pond, although it was also important to check our earlier conclusions (Mann 1989a, 1999; Mann et al. 1999, etc.) and exclude the 
possibility that there are further morphologically distinct $S$. pupula demes in Blackford Pond. The advantage of the Blackford material is that it has been studied in several different ways over a long period ( $>20 \mathrm{yr}$ ) - through investigations of morphology, ultrastructure, mating systems, reproductive isolation, parasitism and molecular systematics - and so we were fairly confident that we knew the 'correct' answer before we began the present morphometric analysis. Besides, we had already undertaken preliminary morphometric analyses that had shown a clear separation of all six Blackford demes (Droop \& Mann 1996). However, other lakes and areas have not been so well studied and it is clear from surveys (e.g. Taylor 1996) that the complexity of variation in some of these far exceeds that in Blackford Pond. In these, therefore, sophisticated morphometric, morphological and molecular studies may be necessary before interpretation is possible. The key stage, however, is during exploration of the variation pattern. If visual inspection of images, or visual assessment of graphed morphometric data (either plotted directly or after summarization, e.g. via PCA or factor analysis) fail to reveal more or less discrete populations (demes) within a sample or taxon, taxonomists are unlikely to consider it worth spending precious time undertaking further studies, e.g. using cultures to obtain material to get molecular systematic data. It is important, therefore, that morphometric tools are sensitive enough to detect significant variation. The Blackford populations, because they are well known, have allowed us to test how well various metrics and analyses perform in the initial exploration of 'difficult' taxa, so that we can have greater confidence in their performance when they are applied to less well understood systems. Morphometric analysis is of course relevant also for identification, once classes of objects have been defined (as in ADIAC: du Buf \& Bayer 2002). This was not our prime purpose in the present study, however, and so we did not apply discriminant analysis.

Contour segment analysis, developed during the ADIAC project (du Buf et al. 1999; du Buf \& Bayer 2002) as part of a suite of morphometric tools for automated identification, has proved to be a highly sensitive morphometric method for investigating variation in the apparently simple valve shapes of the Blackford members of the $S$. pupula complex. Unlike Legendre polynomial shape descriptors, which have fairly obvious counterparts in traditional morphological descriptions [describing features like average standardized width $\left(P_{0}\right)$, lanceolateness $\left(P_{2}\right)$, presence of a median constriction $\left(P_{4}\right)$, 'triundulateness' $\left(P_{6}\right)$, etc.], the parameters derived by contour segment analysis have only a mathematical, not a biological meaning: there is no implication of evolutionary homology and most of the parameters could not be used in cladistic analysis. Contour segment analysis is a method for exploring the variation pattern - and the Blackford data show that in this respect, for $S$. pupula, it can be very powerful - and for discriminating between taxa (Loke \& du Buf 2002).

By contrast, some aspects of shape described by Legendre analysis are clearly related to the ontogeny of the outline during auxospore expansion. For example, lanceolate shapes with high weighting of $P_{2}$ are of ten produced by auxospores that taper as they expand (e.g. Mann \& Stickle 1993), whereas high $P_{4}$ or $P_{6}$ can reflect a more complex sequence of contraction and expansion (e.g. Mann 1989c). This 'biological meaning' makes Legendre analysis attractive, but the Black- ford data suggest that significant discontinuities in variation might be missed if this were the sole method of quantitative shape assessment, though Legendre shape descriptors clearly perform better than cruder measures such as rectangularity (which succeeds in separating the demes in Fig. 14 only because it is coupled with absolute size). As noted already by Mou \& Stoermer (1992), different shape descriptors can be suitable in different types of diatom. For example, the Legendre approach is poorly suited to diatoms like Asterionella Hassall or Tabellaria Ehrenberg ex Kützing, in which long straight sections of outline alternate with sharp curves; for these, Fourier analysis has been shown to be useful (Pappas et al. 2001). Indeed, there is no overall 'best' measure of shape or pattern and, especially in taxonomically difficult groups such as Sellaphora, with subtle variation in morphology, we recommend a many-pronged exploration of the variation pattern, using several different shape descriptors and methods of data analysis and display. The segregate species we describe here on the basis of morphological, morphometric and ultrastructural data - which have also been shown to vary in their mating systems, to be separated by reproductive barriers and to be differentially prone to attack by parasites - are only six out of many others that we have detected within the $S$. pupula species complex. Some of the other demes are very similar morphologically to the 'Blackford six', but careful measurements, ultrastructural detail and molecular sequence data indicate that they are separate (e.g. Taylor 1996; Behnke 2001; Behnke et al. 2004). This means that any discrepancy between the diatoms we describe here and material from other sources - in valve shape and size, stria pattern, stria density, or valve ultrastructure - must be regarded as potentially significant in indicating species separation.

Because the Blackford group are only six out of many demes (putative species) within the $S$. pupula complex, we cannot give dependable differential diagnoses. To aid identification, however, we have included Table 4, which summarizes the morphological characteristics of the six 'Blackford' species, and we have also taken the unusual step (one that we hope will become increasingly common) of supplying an extensive set of extra images of the 'Blackford six' (at http://rbg-web2.rbge.org.uk/ algae/research/research.htm) to supplement the few representative valves that we illustrate here (Figs 4, 17-22). The Internet offers a historic opportunity to improve the dissemination of taxonomic data (and hence the likelihood that taxon delimitation will become more consistent and accurate), especially in organisms like diatoms, where much of the diagnostic detail can be captured in one or a few images.

Valve ultrastructure has proved immensely valuable in diatom systematics (e.g. Round et al. 1990), but in the S. pupula species complex, SEM observations yield only a little extra taxonomically useful information. Some features do not vary within the six species treated here, or in the other demes of the $S$. pupula aggregate that we have examined so far, e.g. simple round areolae, deflected central internal raphe endings, expanded external raphe endings, narrow helictoglossa and polar bars. Some of these are common to all Sellaphora species, whereas others (the polar bars) have a more restricted distribution. The features that do show variation among the Blackford six are the external development of the raphe-sternum (e.g. whether or not it is elevated or flanked by grooves, as in S. obesa and S. blackfordensis) and the exact course of 
the terminal fissures, which is remarkably constant within a single segregate species but varies within the complex as a whole (from smoothly curved in e.g. S. obesa to abruptly, though only slightly, flexed in e.g. S. capitata). The constancy within demes of such subtle features of the terminal fissures suggests that terminal fissure morphology is subject to strong selective constraints related to raphe function. In other demes of the $S$. pupula complex, but not in the Blackford species, flaps of silica (conopea) are present on either side of the raphe-sternum covering grooves as in S. blackfordensis (e.g. Lange-Bertalot \& Genkal 1999, pl. 36, fig. 10) and it is tempting to interpret the raphe-sternum elevation and grooves of $S$. obesa and $S$. blackfordensis as a vestigial conopeum. To test this idea, a reliable phylogeny needs to be generated, which will undoubtedly depend largely on molecular data.

\section{ACKNOWLEDGEMENTS}

The shape analysis methods were developed as part of the Automatic Diatom Identification and Classification project (ADIAC: http://rbg-web2.rbge.org.uk/ADIAC/), financed by the European Union's Marine Science and Technology programme, contract MAS3-CT97-0122. David Mann thanks the Royal Society for an equipment grant enabling purchase of a photomicroscope. We also gratefully acknowledge INTAS grants 93-3605 and 93-3605ext for supporting studies of mating in Sellaphora by Victor Chepurnov and David Mann and BBSRC grants BIO14354 and BIO14262 for supporting the work of Sarah McDonald, Micha Bayer and Stephen Droop. Dave Marshall, Ralph Martin, Paul Rosin and Julia Hicks (University of Cardiff) helped us develop the interactive types interface for the Web. The comments of two reviewers were helpful and are appreciated. This paper is dedicated to Professor Frank Round, belatedly, for his 75th birthday, with thanks for creating the opportunity for the senior author to have a career in diatom research.

\section{REFERENCES}

Abramowitz M. \& Stegun I.A. 1974. Handbook of mathematical functions with formulas, graphs, and mathematical tables. Dover Publications, New York. 1046 pp.

ANONYMOUS 1975. Proposals for a standardization of diatom terminology and diagnoses. Nova Hedwigia, Beiheft 53: 323-354.

Barber H.G. \& HawOrTh E.Y. 1981. A guide to the morphology of the diatom frustule. Freshwater Biological Association, Scientific Publication 44: 1-112.

BAyer M.M., Droop S.J.M. \& MANN D.G. 2001. Digital imaging as a tool in phycological research, with especial reference to microalgae. Phycological Research 49: 263-274.

BEHNKE A. 2001. Analyse variabler Bereiche der rDNA des Artenkomplexes Sellaphora pupula (Bacillariophyceae). Diplomarbeit. Georg-August-Universität, Göttingen, Germany. 128 pp.

Behnke A., Friedl T., Chepurnov V.A. \& Mann D.G. 2004. Reproductive compatibility and rDNA sequence analyses in the Sellaphora pupula species complex (Bacillariophyta). Journal of Phycology 40: 193-208.

Ciobanu A. \& DU BUF J.M.H. 2002. Identification by contour profiling and Legendre polynomials. In: Automatic diatom identification (Ed. by J.M.H. du Buf \& M.M. Bayer), pp. 167-185. World Scientific Publishing, Singapore.

Coleman A.W. 2001. Biogeography and speciation in the Pandorina/
Volvulina (Chlorophyta) superclade. Journal of Phycology 37: 836851 .

Cox E.J. 2001. What constitutes a stauros? A morphogenetic perspective. In: Lange-Bertalot-Festschrift: studies on diatoms (Ed. by R. Jahn, J.P. Kociolek, A. Witkowski \& P. Compère), pp. 303-316. A.R.G. Gantner, Ruggell, Liechtenstein.

DenduangboripanT J. \& CRONK Q.C.B. 2000. High intraindividual variation in internal transcribed spacer sequences in Aeschynanthus (Gesneriaceae): implications for phylogenetics. Proceedings of the Royal Society of London B: Biological Sciences 267: 1407-1415.

DONG Y. \& Hillman G.R. 2001. Three-dimensional reconstruction of irregular shapes based on a fitted mesh of contours. Image and Vision Computing 19: 165-176.

Droop S.J.M. 1994. Morphological variation in Diploneis smithii and D. fusca (Bacillariophyceae). Archiv fïr Protistenkunde 144: 249270.

DROOP S.J.M. \& MANN D.G. 1996. Towards a species concept for diatoms - morphometric and biological studies in the Sellaphora pupula complex from lowland eutrophic waters. In: Abstracts, Ist European Phycological Congress, Cologne, p. 12. Cambridge University Press, Cambridge.

Droop S.J.M., Mann D.G. \& Lokhorst G.M. 2000. Spatial and temporal stability of demes in Diploneis smithii/D. fusca (Bacillariophyta) supports a narrow species concept. Phycologia 39: 527-546.

DU BUF J.M.H. \& BAYER M.M. 2002. Automatic diatom identification. Series in Machine Perception and Artificial Intelligence, vol. 51. World Scientific Publishing, Singapore. 316 pp.

du Buf H., Bayer M.M., Droop S.J.M., Head R., Juggins S., Fischer S., Bunke H., Wilkinson M., Roerdink J.T.B.M., PeCh-Pacheco J.-L., Cristobal G., Shahbazkia H. \& Ciobanu A. 1999. Diatom identification: a double challenge called ADIAC. In: Proceedings of the IOth International Conference on Image Analysis and Processing, Venice, Italy, pp. 734-739. IEEE Computer Society, Los Alamitos, California.

Geitler L. 1932. Der Formwechsel der pennaten Diatomeen (Kieselalgen). Archiv für Protistenkunde 78: 1-226.

Germain H. 1981. Flore des diatomées eaux douces et saumâtres. Boubée, Paris. 444 pp.

Gilmour J.S.L. \& HeSLOP-Harrison J. 1954. The deme terminology and the units of micro-evolutionary change. Genetica 27: 147-161.

Goldman N., Paddock T.B.B. \& Shaw K.M. 1990. Quantitative analysis of shape variation in populations of Surirella fastuosa. Diatom Research 5: 25-42.

Grant W. \& MURISON D.D. 1968. The Scottish national dictionary, designed partly on regional lines and partly on historical principles, and containing all the Scottish words known to be in use or to have been in use since c. 1700 , vol. 7. Scottish National Dictionary Association, Edinburgh. 525 pp.

Greuter W., McNeill J., Barrie F.R., Burdet H.-M., Demoulin V., Filgueiras T.S., Nicolson D.H., Silva P.C., Skog J.E., Trehane P., Turland N.J. \& HawksworTh D.L. 2000. International Code of Botanical Nomenclature (St Louis Code). Koeltz Scientific Books, Koenigstein, Germany. 474 pp.

Guillard R.R. \& Lorenzen C.J. 1972. Yellow-green algae with chlorophyllide c. Journal of Phycology 8: 10-14.

HustedT F. 1911. Beiträge zur Algenflora von Bremen. IV. Bacillariaceen aus der Wumme. Abhandlungen herausgegeben vom Naturwissenschaftlichen Verein zu Bremen 20: 257-315.

Hustedt F. 1927-1966. Die Kieselalgen Deutschlands, Österreichs und der Schweiz unter Berücksichtigung der übrigen Länder Europas sowie der angrenzenden Meeresgebiete. In: Dr L. Rabenhorsts Kryptogamenflora von Deutschland, Österreich und der Schweiz, vol. 7 (3 parts published). Akademische Verlagsgesellschaft, Leipzig, Germany.

Hustedt F. 1930. Bacillariophyta. In: Die Süsswasser-Flora Mitteleuropas, vol. 10, ed. 2 (Ed. by A. Pascher), 466 pp. G. Fischer, Jena, Germany.

Johansen J.R., Lowe R.L., Gomez S.R., KocioleK J.P. \& MAKosky S.A. 2004. New algal species records for the Great Smoky Mountains National Park, U.S.A., with an annotated checklist of all reported algal species for the park. Archiv für Hydrobiologie, Supplement 150 (Algological Studies 111): 17-44. 
Krammer K. \& Lange-Bertalot H. 1986. Bacillariophyceae 1. Teil: Naviculaceae. In: Süsswasserflora von Mitteleuropa, vol. 2/1 (Ed. by H. Ettl, J. Gerloff, H. Heynig \& D. Mollenhauer), G. Fischer, Stuttgart, Germany. 876 pp.

KÜTZING F.T. 1844. Die kieselschaligen Bacillarien oder Diatomeen. W. Köhne, Nordhausen, Germany. 152 pp.

LAJEUNESSE T.C. 2001. Investigating the biodiversity, ecology, and phylogeny of endosymbiotic dinoflagellates in the genus Symbiodinium using the ITS region: in search of a "species level" marker. Journal of Phycology 37: 866-880.

Lange-Bertalot H. \& Genkal S.I. 1999. Diatomeen aus Sibirien I. Inseln im arktischen Ozean (Yugorsky-Shar-Strait). In: Iconographia diatomologica, vol. 6: phytogeography-diversity-taxonomy (Ed. by H. Lange-Bertalot), pp. 7-271. A.R.G. Gantner, Vaduz, Liechtenstein.

LANGe-Bertalot H. \& Metzeltin D. 1996. Oligotrophie-Indikatoren. 800 Taxa repräsentativ für drei diverse Seen-Typen: kalkreicholigodystroph - schwach gepuffertes Weichwasser. In: Iconographia diatomologica, vol. 2: ecology-diversity-taxonomy (Ed. by $\mathrm{H}$. Lange-Bertalot), pp. 3-390. Koeltz Scientitic Books, Koenigstein, Germany.

Lewis C.T. \& ShORT C. 1907. A Latin dictionary. Clarendon Press, Oxford. 2019 pp.

LOKE R.E. \& DU BUF J.M.H. 2002. Identification by curvature of convex and concave segments. In: Automatic diatom identification (Ed. by J.M.H. du Buf \& M.M. Bayer), pp. 141-165. World Scientific Publishing, Singapore.

MANN D.G. 1981. Sieves and flaps: siliceous minutiae in the pores of raphid diatoms. In: Proceedings of the Sixth Symposium on Recent and Fossil Diatoms (Ed. by R. Ross), pp. 279-300. O. Koeltz, Koenigstein, Germany.

MANN D.G. 1984. Observations on copulation in Navicula pupula and Amphora ovalis in relation to the nature of diatom species. Annals of Botany 54: 429-438.

MANN D.G. 1985. In vivo observations of plastid and cell division in raphid diatoms and their relevance to diatom systematics. Annals of Botany 55: 95-108.

MANN D.G. 1988a. The nature of diatom species: analysis of sympatric populations. In: Proceedings of the 9th International Diatom Symposium (Ed. by F.E. Round), pp. 317-327. Biopress, Bristol, UK, and O. Koeltz, Koenigstein, Germany.

MANN D.G. 1988b. Why didn't Lund see sex in Asterionella? A discussion of the diatom life cycle in nature. In: Algae and the aquatic environment (Ed. by F.E. Round), pp. 383-412. Biopress, Bristol, UK.

MANN D.G. 1989a. The species concept in diatoms: evidence for morphologically distinct, sympatric gamodemes in four epipelic species. Plant Systematics and Evolution 164: 215-237.

ManN D.G. 1989b. The diatom genus Sellaphora: separation from Navicula. British Phycological Journal 24: 1-20.

MANN D.G. 1989c. On auxospore formation in Caloneis and the nature of Amphiraphia (Bacillariophyta). Plant Systematics and Evolution 163: 43-52.

MANN D.G. 1999. The species concept in diatoms (Phycological Reviews 18). Phycologia 38: 437-495.

MANN D.G. 2001. The systematics of the Sellaphora pupula complex: typification of S. pupula. In: Lange-Bertalot-Festschrift (Ed. by R. Jahn, J.P. Kociolek, A. Witkowski \& P. Compère), pp. 225-243. A.R.G. Gantner, Ruggell, Liechtenstein.

MANN D.G. \& DROOP S.J.M. 1996. Biodiversity, biogeography and conservation of diatoms. Hydrobiologia 336: 19-32.

MANN D.G. \& STICKLE A.J. 1988. Nuclear movements and frustule symmetry in raphid pennate diatoms. In: Proceedings of the 9th International Diatom Symposium (Ed. by F.E. Round), pp. 281-289. Biopress, Bristol, UK, and Koeltz Scientific Books, Koenigstein, Germany.

MANN D.G. \& STICKLE A.J. 1993. Life history and systematics of Lyrella. Nova Hedwigia, Beiheft 106: 43-70.

ManN D.G., Chepurnov V.A. \& Droop S.J.M. 1999. Sexuality, incompatibility, size variation, and preferential polyandry in natural populations and clones of Sellaphora pupula (Bacillariophyceae). Journal of Phycology 35: 152-170.
MereschKowsky C. 1902. On Sellaphora, a new genus of diatoms. Annals and Magazine of Natural History, series 7, 9: 185-195.

MölleR M. \& CRONK Q.C.B. 1997. Origin and relationships of Saintpaulia $\mathrm{H}$. Wendl. (Gesneriaceae) based on ribosomal DNA internal transcribed spacer (ITS) sequences. American Journal of Botany 84: 383-404.

Mou D. \& Stoermer E.F. 1992. Separating Tabellaria (Bacillariophyceae) shape groups based on Fourier descriptor analysis. Journal of Phycology 28: 386-395.

NiPKOW F. 1927. Über das Verhalten der Skelette planktischer Kieselalgen im geschichteten Tiefenschlamm des Ziirich- und Baldeggersees. Zeitschrift für Hydrologie, Hydrographie und Hydrobiologie 4: 71-120.

PAPPAS J.L. \& Stoermer E.F. 2003. Legendre shape descriptors and shape group determination of specimens in the Cymbella cistula species complex. Phycologia 42: 90-97.

Pappas J.L., Fowler G.W. \& Stoermer E.F. 2001. Calculating shape descriptors from Fourier analysis: shape analysis of Asterionella (Heterokontophyta, Bacillariophyceae). Phycologia 40: 440-456.

PAtrick R. \& Reimer C.W. 1966. The diatoms of the United States, exclusive of Alaska and Hawaii. Vol. 1. Fragilariaceae, Eunotiaceae, Achnanthaceae, Naviculaceae. Monographs of the Academy of Natural Sciences, Philadelphia 13: 1-688.

Press W.H., Teukolsky S.A., Vetterling W.T. \& Flannery B.P. 1999. Numerical recipes in $C$ : the art of scientific computing, ed. 2. Cambridge University Press, Cambridge, UK. 1020 pp.

Pullan M.R., Watson M.F., Kennedy J.B., Raguenaud C. \& Hyam R. 2000. The Prometheus Taxonomic Model: a practical approach to representing multiple classifications. Taxon 49: 55-75.

Raguenaud C., Pullan M.R., Watson M.F., Kennedy J.B., Newman M.F. \& BARCLAY P.J. 2002. Implementation of the Prometheus Taxonomic Model: a comparison of database models and query languages and an introduction of the Prometheus Object-Orientated Model. Taxon 51: 131-142.

Rhode K.M., Pappas J.L. \& Stoermer E.F. 2001. Quantitative analysis of shape variation in type and modern populations of Meridion (Bacillariophyceae). Journal of Phycology 37: 175-183.

RoshCHIN A.M. 1994. Zhiznennye tsikly diatomovykh vodoroslej. Naukova Dumka, Kiev. 170 pp.

Roshchin A.M. \& Chepurnov V.A. 1999. Dioecy and monoecy in the pennate diatoms (with reference to the centric taxa). In: Proceedings of the 14th International Diatom Symposium (Ed. by S. Mayama, M. Idei \& I. Koizumi), pp. 240-261. Koeltz Scientific Books, Koenigstein, Germany.

Ross R., Cox E.J., Karayeva N.I., Mann D.G., Paddock T.B.B., SimONSEN R. \& Sims P.A. 1979. An amended terminology for the siliceous components of the diatom cell. Nova Hedwigia, Beiheft 64: 513-533.

Round F.E., Crawford R.M. \& Mann D.G. 1990. The diatoms. Biology \& morphology of the genera. Cambridge University Press, Cambridge, UK. $747 \mathrm{pp}$.

SiMONSEN R. 1987. Atlas and catalogue of the diatom types of Friedrich Hustedt, vols. 1-3. J. Cramer, Berlin.

Steinman A.D. \& LAdEwSKı T.B. 1987. Quantitative shape analysis of Eunotia pectinalis (Bacillariophyceae) and its application to seasonal distribution patterns. Phycologia 26: 467-477.

Stoermer E.F. \& LADEwSKI T.B. 1982. Quantitative analysis of shape variation in type and modern populations of Gomphoneis herculeana. Nova Hedwigia, Beiheft 73: 347-386.

Stoermer E.F., QI Y.-Z. \& LAdEwSKI T.B. 1986. A quantitative investigation of shape variation in Didymosphenia (Lyngb.) M. Schmidt. Phycologia 25: 494-502.

TAYLOR N.G. 1996. Variation within Sellaphora pupula (Bacillarioph$y$ ta) in relation to the species concept. MSc thesis. University of Edinburgh, Edinburgh, UK. 52 pp.

THERIOT E. \& LADEWSKI T.B. 1986. Morphometric analysis of shape of specimens from the neotype of Tabellaria flocculosa (Bacillariophyceae). American Journal of Botany 73: 224-229.

Wesenberg-Lund C. 1908. Plankton investigations of the Danish lakes. General part. The Baltic freshwater plankton, its origins and variation. Gyldendalske Boghandel, Copenhagen. 389 pp.

Received 10 February 2003; accepted 8 January 2004

Communicating editor: M. Montresor 